\title{
Production d'éthanol à partir de biomasse lignocellulosique
}

\author{
J.-C. O gier $^{1}$, D. Ballerini², J.-P. Leygue ${ }^{1}$, L. Rigal ${ }^{3}$ et J. Pourquié ${ }^{4}$ \\ 1 Céréaliers de France, 8, avenue du Président W ilson, 75016 Paris - France \\ 2 Institut français du pétrole, 1 et 4, avenue de Bois-Préau, 92852 Rueil-M almaison Cedex - France \\ 3 Institut national polytechnique, École nationale supérieure de chimie de Toulouse, 118, route de Narbonne, 31077 Toulouse Cedex 4 - France \\ 4 Institut national a gronomique Paris-G rignon, Chaire de microbiologie, 78850 Thiverval-Grignon - France
}

\begin{abstract}
Résumé - Cette étude fait le point des connaissances scientifiques et techniques dans le domaine de la production alcoolique à partir de susbstrats lignocellulosiques. Ce travail, réalisé dans le cadre d'Agrice (Agriculture pour la chimie et l'énergie), est une synthèse bibliographique qui a cherché à identifier les avancées capables de débloquer certains verrous technologiques et économiques liés à ce type de procédé.

La biomasse lignocellulosique est un substrat complexe, constitué des trois principales fractions que sont la cellulose, les hémicelluloses et la lignine. Le procédé de production d'éthanol consiste à récupérer par hydrolyse le maximum de sucres issus à la fois des fractions cellulosiques et hémicellulosiques, puis de fermenter ces sucres en éthanol. Les premiers procédés d'hydrolyse utilisés étaient surtout chimiques, mais ils sont peu compétitifs à l'heure actuelle, en raison notamment du coût des réactifs et de la formation de nombreux sousproduits et de composés inhibiteurs rendant les hydrolysats peu fermentescibles. Ils sont désormais concurrencés par les procédés enzymatiques, plus spécifiques et qui permettent de meilleurs rendements d'hydrolyse dans des conditions moins sévères.
\end{abstract}

Cependant, la biomasse lignocellulosique n'est pas directement accessible aux enzymes, et elle doit subir au préalable une phase de prétraitement dont l'objectif est d'améliorer la susceptibilité à l'hydrolyse enzymatique de la cellulose et éventuellement d'hydrolyser la fraction hémicellulosique en sucres monomères. Parmi les nombreuses méthodes de prétraitement qui ont été étudiées, nous en avons identifié trois répondant au mieux aux objectifs précédemment cités : le prétraitement à l'acide dilué, l'explosion à la vapeur avec utilisation d'un catalyseur, et la thermohydrolyse. Ces trois méthodes permettraient d'atteindre des rendements d'hydrolyse enzymatique de la cellulose proches de $100 \%$, tout en permettant un taux d'hydrolyse des hémicelluloses supérieur à $80 \%$, et en minimisant la formation de composés de dégradation.

L'hydrolyse enzymatique doit encore être améliorée afin de réduire le coût lié à la consommation d'enzymes. Les principales voies de recherche devraient porter sur l'amélioration de l'activité des cellulases, afin de se rapprocher le plus possible de celles d'enzymes telles que les amylases. Le développement du procédé SFS (saccharification et fermentation simultanées) permet d'améliorer l'efficacité des enzymes en minimisant les réactions d'inhibition des enzymes par les produits formés. Son inconvénient est lié aux différences entre les températures optimales de l'hydrolyse enzymatique et de la fermentation. La recherche de micro-organismes conservant de bonnes performances fermentaires à température élevée doit donc se poursuivre.

Un autre verrou technologique du procédé concerne la fermentation alcoolique des pentoses, qui peuvent représenter jusqu'à 25 à $40 \%$ des sucres totaux contenus dans la biomasse lignocellulosique. C'est pourquoi il est indispensable de les valoriser en éthanol. Contrairement à la fermentation alcoolique du glucose, largement connue et maîtrisée, celle des pentoses n'est toujours pas résolue en raison des performances fermentaires médiocres des micro-organismes utilisés. Le développement des outils génétiques et les nouvelles voies de recherche portant sur la transformation de Saccharomyces cerevisiae et de Zymomonas mobilis afin de leur faire acquérir la capacité à fermenter les pentoses, devraient permettre d'améliorer les performances, et éventuellement de se rapprocher de celles enregistrées sur glucose par Saccharomyces cerevisiae. 


\begin{abstract}
Ethanol Production from Lignocellulosic Biomass - The reported study intends to describe the state of the art in the domain of ethanol production from lignocellulosic biomass. It was sustained and managed by a specialized group of the French Agrice (Agriculture for Chemical and Energy Organization). Its first goal was to pinpoint the main technical and economical bottlenecks of the processes which are today under consideration, and to identify which research and development efforts could be implemented to overcome them (in the short or middle term).

Lignocellulosic biomass is a complex substrate, and essentially made of cellulose, hemicellulose and lignin. The processes which have been considered, attempt to recover a maximum amount of sugars from the hydrolysis of cellulose and hemicellulose, and to ferment them into ethanol.

The hydrolysis processes used in the past are essentially chemical processes, but the acid recovery costs and the formation of toxic products make them uncompetitive. They are now substituted by enzymatic processes, which are more specific and allow higher hydrolysis yields under less severe conditions.

However, the cellulose that is the target of the enzymatic hydrolysis, is not directly accessible to the enzymes. It is the reason why a pretreatment step has to precede the enzymatic hydrolysis, in order to improve the enzymatic susceptibility of the cellulose, and to hydrolyse the hemicellulosic fraction. Different types of pretreatment have been studied, but three methods appear more efficient: dilute acid hydrolysis, steam explosion with catalyst addition and thermohydrolysis. These pretreatments could result in high hydrolysis yields of the cellulose fraction (close to 100\%), and in a maximum recovery of the sugars from the hemicellulosic fraction.

Enzymatic hydrolysis has yet to be improved in order to reduce the cost of consumption of the enzymes. Research works will have to focus upon the enzyme specific activity, in order to achieve higher efficiencies such as those obtained with amylases. The SSF (Saccharification and Simultaneous Fermentation) process improves the enzyme efficiency by reducing the feed-back inhibition from the hydrolysis products. The screening of efficient fermentative microorganisms under high temperature conditions $\left(45^{\circ} \mathrm{C}\right)$ has thus to be further implemented.

The last technological barrier of the process concerns the ethanolic fermentation of the pentoses. Indeed, the pentoses, originating from the hemicellulosic fraction, can represent up to $40 \%$ of total sugars in some lignocellulosic substrates. Nobody has yet identified a microorganism which is able to ferment the pentoses into ethanol with performances similar to those of Saccharomyces cerevisiae on glucose. But recent genetic improvements focused on the transformation of Saccharomyces cerevisiae and Zymomonas mobilis could result in good fermentative performances on pentoses.
\end{abstract}

Keywords: ethanol, lignocellulosic biomass.

\section{IN TRO DUCTIO N}

La biomasse lignocellulosique représente une des ressources renouvelables les plus abondantes sur terre, et certainement une des moins coûteuses. Sa conversion en éthanol à usage carburant devrait permettre de subvenir à une partie des besoins énergétiques, couverts jusqu'à présent essentiellement par les produits dérivés du pétrole, tout en générant de nouvelles opportunités pour le monde agricole.

Les substrats considérés sont très variés, puisqu'ils concernent à la fois les substrats ligneux (feuillus et résineux), les sous-produits de l'agriculture (paille) ou ceux des industries génératrices de déchets lignocellulosiques (industries agroalimentaires, papeteries).

La biomasse lignocellulosique est composée de trois principales fractions. La première, de l'ordre de 35 à $50 \%$, est la cellulose qui est un polymère de glucose. La seconde, appelée fraction hémicellulosique, de l'ordre de 20 à $30 \%$, est aussi un polysaccharide, essentiellement constitué de pentoses (dont le xylose et l'arabinose) et de glucose. La troisième est la lignine (15 à $25 \%$ ), polymère de structure complexe à base de groupements phényls.
La figure 1 représente les principales étapes de la conversion des matériaux lignocellulosiques en éthanol, selon deux variantes : l'une principalement associée à l'obtention des sucres fermentescibles par voie chimique, l'autre par voie enzymatique à l'aide des cellulases. Dans le second cas, un prétraitement s'avère nécessaire pour faciliter les étapes ultérieures d'hydrolyse. Ce prétraitement peut être mécanique, thermique ou chimique, ou bien la combinaison de deux ou trois de ces types d'action.

Les produits résultant du prétraitement, qui peuvent être éventuellement séparés, sont une solution d'hémicelluloses ou de pentoses et un résidu solide principalement constitué de cellulose et de lignine.

L'optimisation de ce type de prétraitement va se traduire par la libération des sucres de la fraction hémicellulosique, essentiellement des pentoses, en minimisant la genèse de produits de dégradation non fermentescibles. En ce qui concerne l'hydrolyse enzymatique de la cellulose, il est crucial, d'un point de vue économique, de diminuer les quantités d'enzymes utilisées.

Si la fermentation alcoolique du glucose est bien connue et déjà largement appliquée au stade industriel, il n'en est 


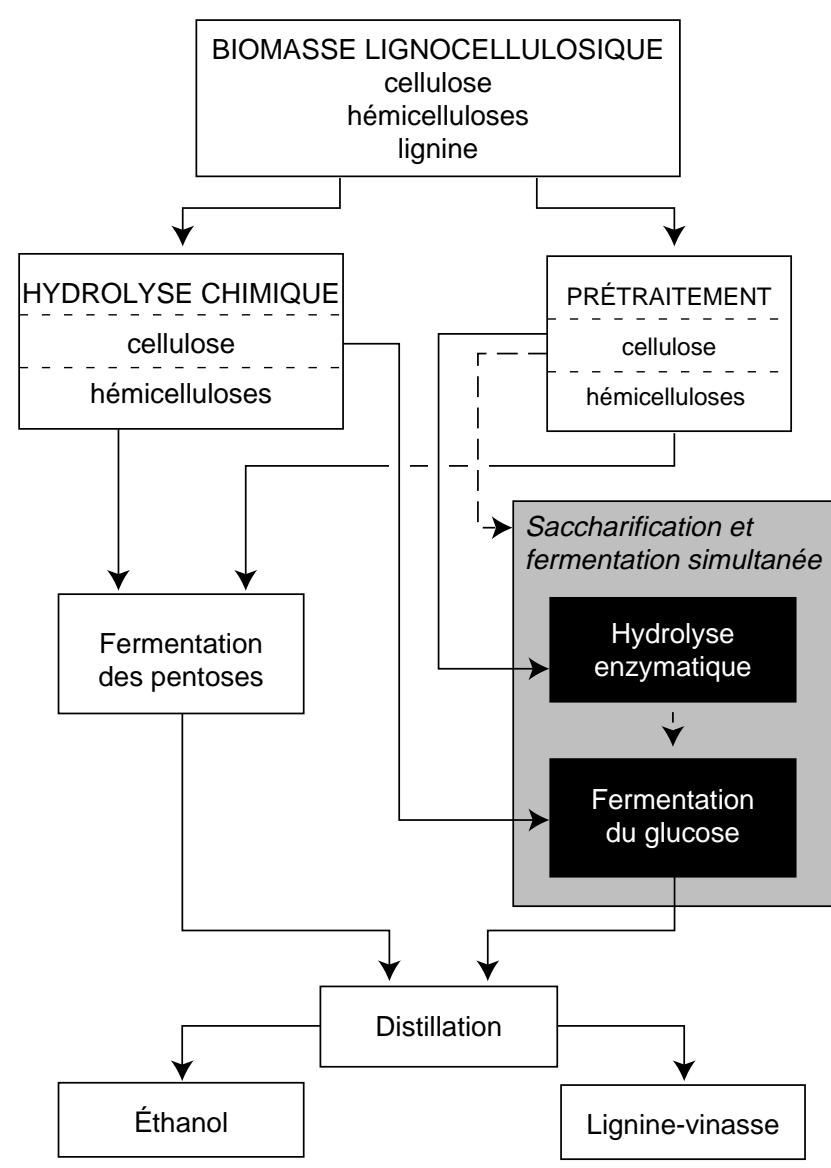

Figure 1

Schéma simplifié de la production d'éthanol à partir de biomasse lignocellulosique.

Block flow diagram of the overall process for converting lignocellulosic biomass to ethanol.

pas de même de celle des pentoses. En effet, les microorganismes étudiés présentent des performances nettement inférieures à celles obtenues par exemple avec la levure $S$. cerevisiae sur glucose. Ceci représente l'un des points faibles du procédé.

L'objectif de cette étude bibliographique, réalisée dans le cadre du groupement d'intérêt scientifique Agrice (Agriculture pour la chimie et l'énergie) était de faire le point sur les travaux déjà réalisés et sur les études en cours, dans les différents domaines associés au processus de conversion de la biomasse lignocellulosique en éthanol.

Dans la perspective de nouvelles voies d'approche, il s'agissait donc d'examiner les avancées capables de débloquer certains verrous technologiques mais avant tout économiques, identifiés tant au niveau du prétraitement, de l'hydrolyse qu'à celui de la fermentation alcoolique des pentoses.

\section{PROCÉDÉS D'HYDRO LYSE CHIMIQ UE}

Ces procédés utilisent un ou plusieurs réactifs chimiques dans le but d'hydrolyser à la fois les hémicelluloses et la cellulose. Les hémicelluloses de structure hétérogène et de faible degré de polymérisation sont hydrolysées en premier $[1,2]$. Quant à l'hydrolyse de la cellulose, elle est rendue plus difficile par sa structure cristalline et son étroite association avec la lignine. L'un des objectifs majeurs de ces procédés est d'aboutir à une hydrolyse totale de la cellulose, tout en évitant des conditions trop sévères susceptibles d'entraîner la dégradation des sucres.

\subsection{Hydrolyse à l'acide dilué}

Cette technique utilise une concentration modérée d'acide ( 0,5 à $1,5 \%$ d'acide sulfurique exprimé par rapport à la matière sèche présente), à des températures comprises entre 180 et $240^{\circ} \mathrm{C}$, pour une durée d'hydrolyse variant de quelques secondes à quelques minutes dans le cas de réacteurs "piston" [3]. Le rendement maximal en glucose est alors de 55-60\% [4-6], mais l'essentiel des pentoses est transformé en furfural $[6,7]$.

Les procédés par percolation ont d'abord été développés durant les années 1930 à 1940 [8]. Avec ces procédés qui opèrent à plus faible température $\left(150-180^{\circ} \mathrm{C}\right)$, il y a peu de produits de dégradation, et des rendements honorables peuvent être obtenus par recyclage de la phase liquide dans le réacteur. Cependant, les nombreux lavages à l'eau, nécessaires pour aboutir à une extraction totale des sucres, ont pour effet de diminuer la concentration finale [9].

Afin d'améliorer le taux de récupération et la concentration des sucres dans les hydrolysats, il a semblé indispensable de réaliser l'hydrolyse de la cellulose et des hémicelluloses en deux étapes séparées, et de prévoir une étape intermédiaire de récupération des produits issus de l'hydrolyse des hémicelluloses. Une première étape à $140-160^{\circ} \mathrm{C}$ permettait d'hydrolyser les hémicelluloses, une deuxième étape à $160-180^{\circ} \mathrm{C}$ permettait d'hydrolyser la cellulose. Avec cette approche en deux étapes, le taux de récupération des sucres était compris entre 70 et $80 \%$, et la concentration en glucose pouvait atteindre 12 à $14 \%$ [3].

Afin d'éviter la phase d'extraction des pentoses, le NREL (National Renewable Energy Laboratory, États-Unis) a expérimenté, en laboratoire, une technique simulant un processus continu à contre-courant $[10,11]$, par l'utilisation de plusieurs réacteurs batch en série (préhydrolyse à $150^{\circ} \mathrm{C}$ pendant $30 \mathrm{~min}$, hydrolyse à $183^{\circ} \mathrm{C}$ pendant $100 \mathrm{~min}$, concentration acide de $0,7 \%$ ). Le procédé a permis d'atteindre un taux de récupération des sucres de $80 \%$, avec une concentration en sucres de $20 \%$ supérieure à celle obtenue avec le réacteur à percolation.

Le NREL [12] a ensuite développé en pilote industriel (fig. 2) un procédé multiétagé utilisant également ce concept 


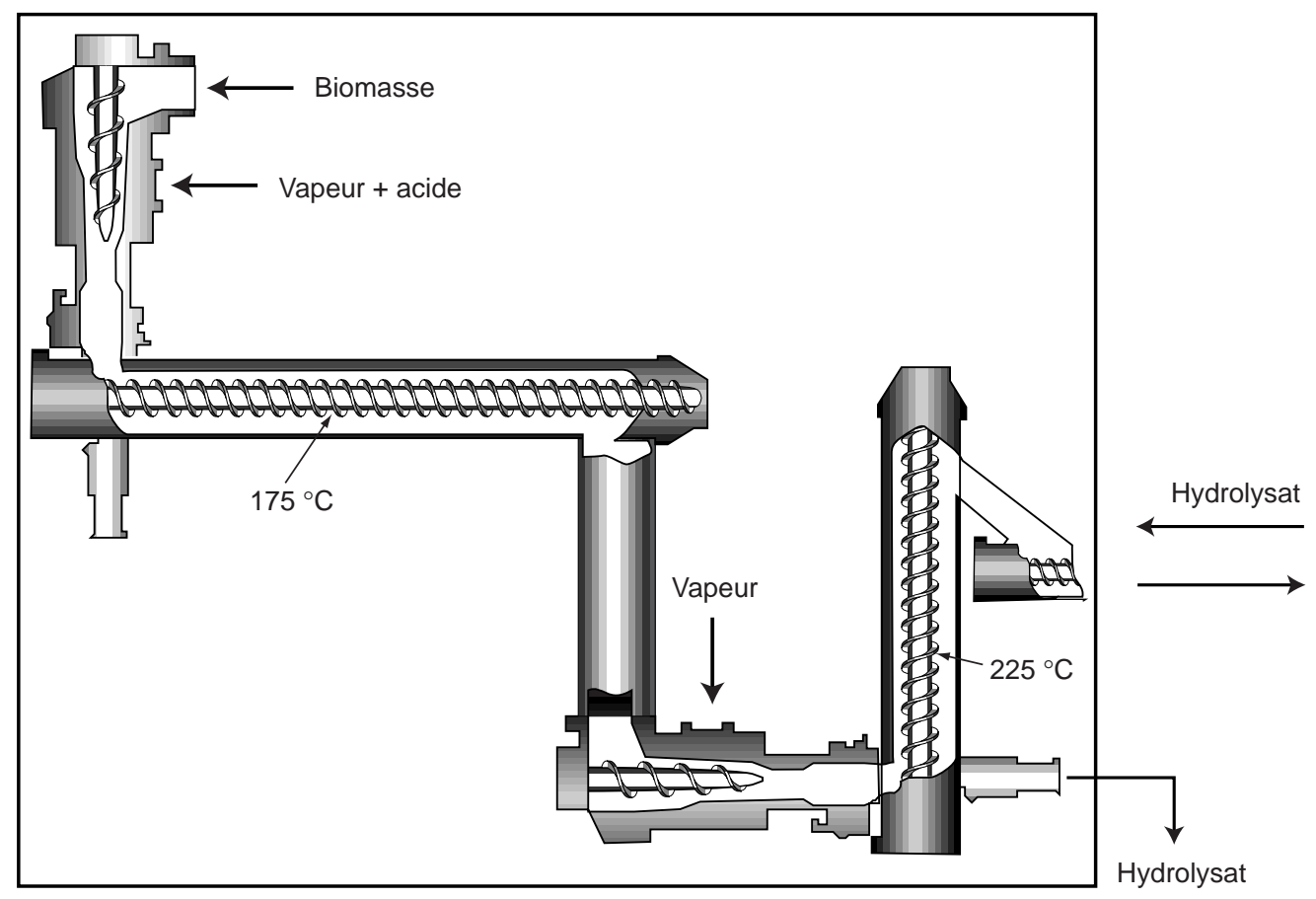

Étage 1

Étage 2

Étage 3

Figure 2

Schéma du procédé multiétage d'hydrolyse à acide dilué développé par le NREL (d'après Elander et al., 1997).

The several step NREL process configuration using dilute acid cellulose hydrolysis technology to produce ethanol from biomass (by Elander et al., 1997).

de circulation à contre-courant. La solution acide circule dans le sens des températures décroissantes, alors que la biomasse circule dans le sens des températures croissantes, ce qui permet de minimiser les temps de séjour des sucres à des températures élevées. Il en résulte une plus faible dégradation des sucres en composés inhibiteurs. Ce procédé pilote comporte trois étages, et il a été testé avec de la sciure de peuplier. Le premier étage est opéré à contre-courant à $175^{\circ} \mathrm{C}$ et aboutit à une hydrolyse de $70 \%$ de la fraction hémicellulosique; le second étage est opéré à $225^{\circ} \mathrm{C}$ à contre-courant après élimination de la phase liquide et éventuellement lavage. Il permet d'obtenir l'hydrolyse de la fraction hémicellulosique résiduelle et de $60 \%$ de la fraction cellulose. La technologie mise en œuvre dans le troisième étage est optionnelle (fig. 2).

La société Bertin (France) a également mis au point un pilote utilisant cette technologie d'hydrolyse à acide dilué [13]. Ce procédé utilisait un réacteur continu à percolation permettant une circulation liquide solide à contre-courant. Pour des raisons économiques, ce pilote n'a jamais connu de développement industriel.

L'université de New York [14] a mis au point un réacteur bi-vis adapté à l'hydrolyse à acide dilué des substrats lignocellulosiques. Les rendements rapportés concernant la récupération du glucose étaient respectivement de $55 \%$ sur pulpe de papier, et $60 \%$ sur sciure de bois.

Les avantages des procédés d'hydrolyse à l'acide dilué sont liés d'une part à l'utilisation d'une concentration élevée en biomasse, d'où une concentration en sucres plus importante dans les hydrolysats [3], et d'autre part à l'absence de recyclage de l'acide.

En résumé, l'hydrolyse à l'acide dilué conduit à des rendements faibles, et ne permet de récupérer généralement que 60 à $70 \%$ des sucres totaux. Les hydrolysats produits en milieu acide dilué sont difficiles à fermenter, en raison de la présence en proportion importante de composés inhibiteurs : furfural, hydroxyméthylfurfural, acide acétique, etc. [15]. Les conditions acides et les températures élevées conduisent généralement à la dégradation des sucres et la formation de nombreux composés inhibiteurs. Un autre inconvénient de ce procédé est lié aux réactions de réversion des sucres, se traduisant par une repolymérisation en oligosaccharides non fermentescibles. Enfin, ce type de procédé pose deux problèmes technologiques majeurs. D'une part, l'utilisation d'acide sulfurique dilué à des températures de $180-240^{\circ} \mathrm{C}$ peut entraîner la corrosion des matériaux. D'autre part, le soutirage d'une matière lignocellulosique dans un réacteur continu sous pression n'est pas une opération aisée. 


\subsection{Hydrolyse à l'acide concentré}

Ces procédés ont fait l'objet de développements industriels dans des conditions particulières (économie de guerre). Leur faible rentabilité a entraîné leur abandon. Néanmoins, nous rappelons brièvement dans ce chapitre le principe et les résultats les plus importants concernant l'utilisation de cette technique.

Ces procédés opèrent à faibles températures, évitant la production de produits de dégradation, et permettant d'atteindre des rendements de récupération des sucres proches de $100 \%$. Le procédé Bergius utilisait de l'acide chlorhydrique $(\mathrm{HCl})$ concentré en réacteur continu afin de faciliter sa récupération. L'hydrolyse se faisait à $35^{\circ} \mathrm{C}$ pendant une heure, avec un rendement de $100 \%$ pour les sucres facilement hydrolysables. Malheureusement, $\mathrm{HCl}$ est très difficilement recyclable et très corrosif [3], et son utilisation dans ce domaine est désormais abandonnée.

L'utilisation de l'acide fluorhydrique gazeux a été proposée $[16,17]$. Il permettrait d'atteindre des rendements de récupération des sucres de $100 \%$, mais c'est un réactif 5 fois plus cher que $\mathrm{HCl}$ et encore plus toxique [3].

L'emploi de l'acide sulfurique $\left(\mathrm{H}_{2} \mathrm{SO}_{4}\right)$ concentré a été la voie la plus étudiée, car il s'agit d'un réactif nettement moins onéreux. Au Japon, un pilote utilisant de $1^{\prime} \mathrm{H}_{2} \mathrm{SO}_{4}$ concentré, avec une technique de recyclage des acides par des membranes, a été testé [3]. Mais la difficulté de mise en œuvre de cette technique a pénalisé fortement l'extrapolation à l'échelle industrielle.

Les points forts de ces procédés sont :

- l'obtention de rendements d'hydrolyse de $100 \%$ pour la fraction cellulosique ;

- l'obtention d'hydrolysats concentrés en sucres ;

- la possibilité de travailler à basse pression et température modérée.

Cependant, le prix des acides et le coût de leur recyclage sont encore bien trop élevés pour en faire une technique compétitive sur le plan économique. Par ailleurs, la mise en œuvre d'acide concentré pose le problème de la corrosion des matériels, du contrôle strict des conditions opératoires les plus douces possible pour éviter la formation de produits de dégradation.

\subsection{Combinaison d'une hydrolyse à l'acide dilué et d'une hydrolyse à l'acide concentré}

Généralement, la combinaison entre l'hydrolyse à l'acide dilué et l'hydrolyse à l'acide concentré permet de meilleurs rendements que le procédé à un seul étage, à la fois en termes d'hydrolyse des hémicelluloses et de la cellulose.

- $1^{\text {er }}$ étage : au cours de cette étape, il est important de travailler avec un acide dilué à température modérée afin de limiter la dégradation du xylose, en particulier en furfural, toxique pour les levures [18].

- $2^{\mathrm{e}}$ étage : un traitement de $10 \mathrm{~min}$ à une concentration en acide de $85 \%$ à $100^{\circ} \mathrm{C}$ apparaît être le plus approprié [18].
Des rendements proches du maximum $(95 \%$ de récupération pour les sucres issus à la fois des fractions cellulosiques et hémicellulosiques) ont été obtenus avec une préhydrolyse à l'acide dilué $\left(4,4 \%\right.$ d' $\mathrm{H}_{2} \mathrm{SO}_{4}$ à $100{ }^{\circ} \mathrm{C}$ pendant $\left.60 \mathrm{~min}\right)$ suivie d'une hydrolyse de la cellulose à l'acide concentré $(85 \%$ $\mathrm{d}^{\prime} \mathrm{H}_{2} \mathrm{SO}_{4}$ à $100^{\circ} \mathrm{C}$ pendant $10 \mathrm{~min}$ ) [18].

\subsection{Conclusion}

Cette étude sur les procédés d'hydrolyse chimique montre que la principale difficulté réside dans l'hydrolyse acide de la cellulose. Celle-ci requiert des conditions relativement sévères si l'on veut obtenir des rendements honorables. Ces conditions se traduisent par des coûts d'investissement qui pénalisent fortement l'économie du procédé. D'autre part, ce type de procédé nécessite un traitement de neutralisation du résidu acide à la chaux éteinte, générant des produits peu exploitables ou même des déchets [19].

Par contre, la préhydrolyse acide des hémicelluloses semble plus aisée et moins coûteuse, d'où son intérêt en tant que méthode de prétraitement pour l'hydrolyse enzymatique.

\section{MÉTHO DES DE PRÉTRAITEMENT POUR L'HYDRO LYSE EN ZYMATIQUE}

\subsection{0 bjectifs des prétraitements}

La cellulose (et éventuellement les hémicelluloses), qui sont les cibles de l'hydrolyse enzymatique, ne sont pas directement accessibles aux enzymes. C'est la raison pour laquelle un prétraitement de la biomasse doit précéder l'étape d'hydrolyse enzymatique.

Le prétraitement vise à modifier les propriétés physiques et physicochimiques du matériau lignocellulosique, et donc de la fraction cellulosique, telles que son degré de polymérisation ou son état de cristallinité. D'un point de vue économique, il semble préférable que le prétraitement conduise à une hydrolyse totale des hémicelluloses, de façon à récupérer les pentoses et les valoriser séparément de la fraction cellulosique. L'hydrolyse des hémicelluloses dépend des conditions opératoires utilisées au cours du prétraitement : de fortes températures augmentent la cinétique de solubilisation des hémicelluloses et des temps de réaction plus faibles limitent la dégradation des sucres et la production de composés inhibiteurs [20]. La fraction hémicellulosique ainsi solubilisée est extraite du matériel prétraité par une étape d'extraction à l'eau.

La lignine peut être extraite de la fraction insoluble par une solution alcaline [21]. L'extraction totale du résidu alcalin contenant encore de la lignine par l'action d'agents oxydants tels que le péroxyde d'hydrogène [22] améliore les rendements lors de l'étape ultérieure d'hydrolyse enzymatique du substrat prétraité, à la fois pour les substrats résineux et les feuillus. Pour d'autres auteurs [23], l'extraction de la 
lignine ne serait pas nécessaire pour améliorer la digestibilité enzymatique de la cellulose. Cependant, elle permet de diminuer le volume du réacteur d'hydrolyse, de diminuer la consommation en énergie lors de l'étape d'hydrolyse de la cellulose, et d'augmenter la concentration des sucres dans la solution.

Le prétraitement préconisé doit être rapide et efficace à fortes concentrations en substrats, et les pertes de matières doivent être minimales. D'autre part, la nature du prétraitement doit être compatible avec l'utilisation d'un matériel simple et peu onéreux. Enfin, les coûts de fonctionnement devront être les plus faibles possible, notamment en consommation de vapeur, électricité et réactifs chimiques.

\subsection{Prétraitements physiques}

Ils ont pour but de réduire le degré de polymérisation de la cellulose et de la lignine, et surtout d'augmenter les surfaces accessibles par les enzymes. Un broyage mécanique intense améliore la digestibilité enzymatique de la cellulose, mais à des coûts d'investissement et d'énergie rédhibitoires pour l'économie du procédé [24-26], en raison des très faibles granulométries requises pour observer des effets significatifs. Par ailleurs, les techniques d'irradiation ont été décrites comme inefficaces, lentes, coûteuses en énergie et économiquement non viables [25-27].

\subsection{Prétraitements physicochimiques}

\subsubsection{Prétraitements par explosion à la vapeur}

$\mathrm{Au}$ cours du prétraitement à la vapeur, le végétal est porté rapidement à haute température $\left(180^{\circ}-240^{\circ} \mathrm{C}\right)$ par injection de vapeur sous pression. L'arrêt du traitement s'effectue par décompression brutale [28]. Les temps de séjour varient de 10 secondes à quelques minutes, pour des pressions allant de 10 à 50 bar. Cette technique a été mise en œuvre soit en discontinu (procédé Iotech issu du procédé papetier Massonite), soit en continu (procédé Stake, fig. 3).

Le traitement aboutit à une hydrolyse partielle de l'hémicellulose (autohydrolyse due à la libération des groupements acétyl), à une fusion des lignines et à une déstructuration intense de la paroi végétale, augmentant les surfaces accessibles pour les enzymes [28]. Il s'accompagne d'une diminution du degré de polymérisation, mais également d'une augmentation de l'indice de cristallinité de la cellulose [29, 30]. C'est une des techniques les plus étudiées et de nombreuses revues sur l'explosion à la vapeur en font état [31-34]. L'efficacité du prétraitement dépend fortement de la température utilisée. D'après Ramos et al. (1992), le taux de conversion enzymatique de la cellulose est de $54 \%$ si la température du prétraitement est de $180^{\circ} \mathrm{C}$, et de $88 \%$ si celle-ci est de $240{ }^{\circ} \mathrm{C}$.

Les principales expérimentations mettant en œuvre cette technique à l'échelle pilote ont été réalisées sur la plate-forme de Soustons en France [34-37]. Celle-ci est née d'un groupement d'intérêt économique Ascaf(Association pour le développement des carburants par la fermentation) entre 1'IFP (Institut français du pétrole) et l'AFME (Agence française pour la maîtrise de l'énergie). L'objectif était la réalisation d'un procédé de conversion de la biomasse lignocellulosique à grande échelle puisque le pilote permettait de traiter jusqu'à une tonne de substrat par heure. Le prétraitement par explosion à la vapeur était réalisé suivant un mode continu par la machine Stake [38]. Selon les conditions mises en œuvre, il conduisait à une solubilisation et à une hydrolyse plus ou moins complète des hémicelluloses, et libérait les fibres de cellulose de la lignine protectrice [38]. Les substrats expérimentés étaient des coproduits de l'agriculture (paille de céréales, tiges de maïs, etc.) ou différentes espèces de ligneux (peuplier, pin).

Il existe encore une installation pilote, située en Italie du Sud, et appartenant à l'Enea, qui peut traiter jusqu'à $300 \mathrm{~kg} / \mathrm{h}$ de peuplier. Le taux de récupération maximal des pentoses a été de $61 \%$, pour des conditions de traitement de $215^{\circ} \mathrm{C}$ pendant 3 min [39]. Ces mêmes conditions ont permis d'extraire $88 \%$ de la lignine du produit prétraité. La digestibilité enzymatique du résidu cellulosique n'a pas été rapportée.

L'explosion à la vapeur a souvent été décrite comme une des méthodes les plus efficaces pour le fractionnement et le prétraitement de la biomasse lignocellulosique [20, 40, 41], du fait :

- de sa simplicité de mise en œuvre dans le cas d'un procédé batch ;

- de l'absence de réactifs chimiques ajoutés ;

- de son adaptation au traitement de particules de grande taille (copeaux).

Cependant, le taux de solubilisation des hémicelluloses reste souvent inférieur à $60 \%$ du rendement théorique [42-45]. En outre, les hémicelluloses, majoritairement hydrolysées sous forme de dimères ou d'oligomères, le sont peu sous forme de monomères. Quant aux rendements d'hydrolyse enzymatique de la cellulose, ils n'excèdent pas $50 \%$ dans la plupart des cas.

D'autre part, l'explosion à la vapeur, opérant à des températures élevées, conduit à des réactions de pyrolyse de la cellulose, et à la formation de composés inhibiteurs [46]. Des temps de réaction courts et des températures faibles sont favorables à la récupération des pentoses, mais le taux d'hydrolyse enzymatique de la cellulose est alors faible [31]. Des pertes de matières sèches peuvent être importantes (10 à $30 \%$ de la matière sèche en fonction des conditions opératoires) [19]. Enfin, ce procédé est peu efficace pour le traitement des résineux [20].

\subsubsection{Thermohydrolyse}

Il s'agit simplement d'une cuisson à l'eau sous forte pression, et le procédé fonctionne donc comme un simple autoclave (procédé discontinu). Cette technique conduirait à une solubilisation complète des hémicelluloses et une solubilisation 


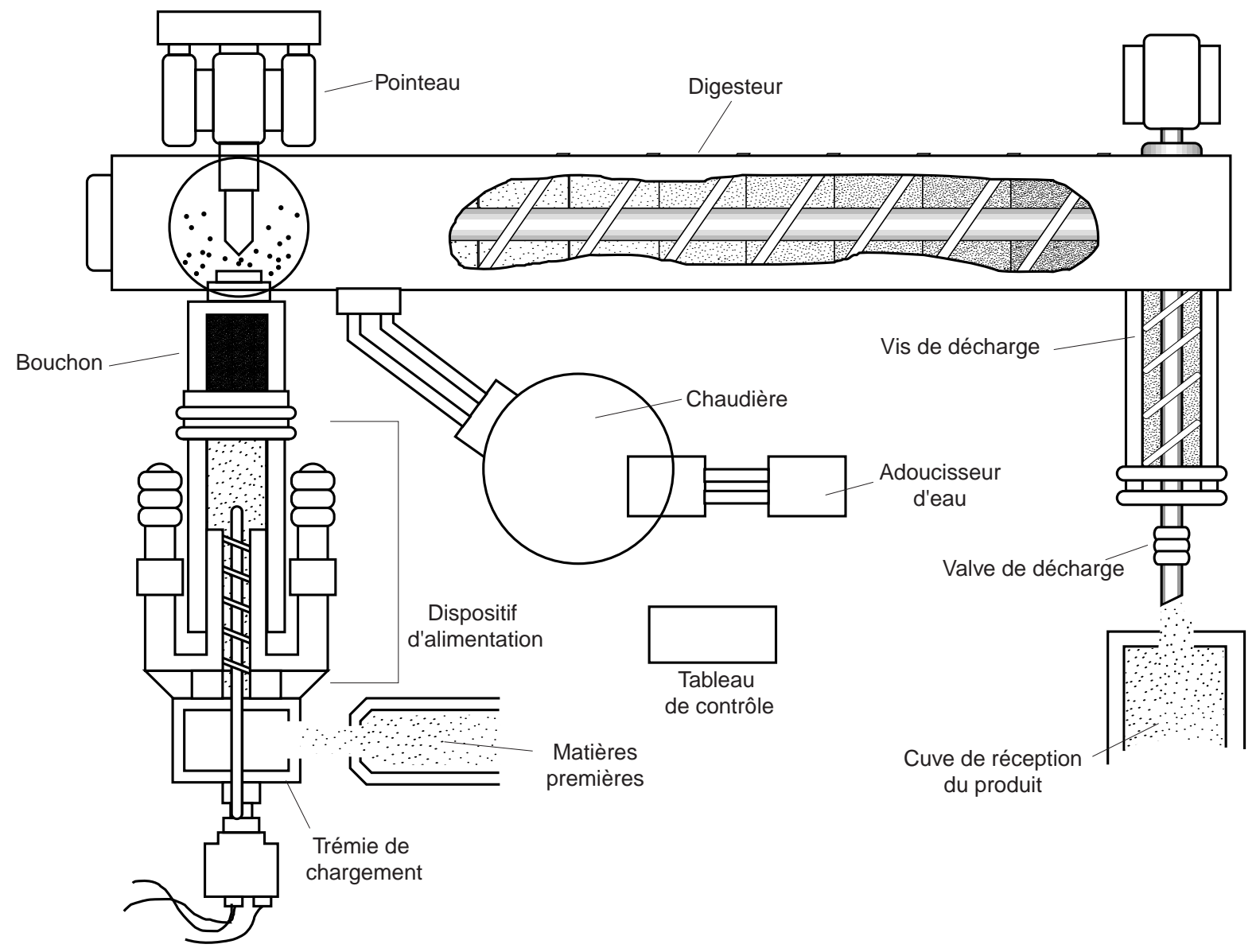

Figure 3

Schéma du procédé Stake.

The Stake process.

significative de la lignine [47]. Cette technique a été initialement développée par l'équipe de Bobleter en Autriche [54], puis expérimentée par Bouchard et al. [48, 49] et Walch et al. [50].

Mok et Antal [51] ont testé 10 substrats (ligneux et herbacés) avec ce procédé de thermohydrolyse (15 min à 200$230^{\circ} \mathrm{C}$ ). Dans tous les cas, les hémicelluloses étaient entièrement solubilisées, et l'hydrolyse enzymatique aboutissait à des rendements en sucres monomères de l'ordre de $95 \%$.

Une nouvelle approche de la thermohydrolyse a été proposée par Kohlmann et al. [52] avec contrôle du pH. Ces conditions avaient pour objectif de favoriser l'hydrolyse enzymatique de la cellulose, grâce à une augmentation de la taille des pores, et une diminution de l'indice de cristallinité [53]. Ils ont utilisé des temps de réaction compris entre 50 et $60 \mathrm{~min}$, permettant des rendements d'hydrolyse enzymatique de la cellulose proches du maximum.

Dans des travaux récents [47], l'équipe de Van Walsum a mis au point une technique de prétraitement par thermohydrolyse applicable à divers substrats. Le taux de récupération des pentoses était supérieur à $80 \%$. La SFS (saccharification et fermentation simultanées) pratiquée ensuite sur le résidu de thermohydrolyse, a permis de convertir $90 \%$ de la cellulose en éthanol, après un temps de séjour de $75 \mathrm{~h}$, une concentration en enzymes de 15 UPF (unité papier filtre/g) et une concentration en substrat dépassant les $100 \mathrm{~g} / \mathrm{l}$. Ces résultats sont intéressants, mais ils n'ont été obtenus à l'heure actuelle qu'à l'échelle du laboratoire.

Ainsi, la thermohydrolyse apparait comme une technique de prétraitement particulièrement attractive du fait :

- de l'absence de produits chimiques ajoutés ;

- des taux de récupération en pentoses élevés ;

- de la bonne digestibilité enzymatique de la cellulose prétraitée ;

- de l'absence de broyage préalable du substrat ;

- des concentrations en matière lignocellulosique élevées (> 100g/l);

- de l'absence de produits inhibiteurs générés ;

- d'une minimisation des déchets issus du prétraitement. 
Cependant, cette méthode n'a été testée que rarement sur pilote industriel, sauf par Bobleter et al. [54], qui ont travaillé avec un réacteur batch de 50 litres. Son intérêt économique n'a donc pas encore été validé. En particulier, la nécessité de travailler à hautes pressions (supérieures à 50 bar) pourrait rendre difficile l'extrapolation à l'échelle industrielle.

\subsection{Prétraitements chimiques}

\subsubsection{Prétraitements en milieu alcalin}

Ils se rapprochent des procédés papetiers, et ont, pour la plupart, été développés avec des pilotes de l'industrie papetière. De nombreuses études ont été réalisées, soit avec uniquement de la soude [55], soit avec de la soude et d'autres produits chimiques [56-60]. Les conditions habituelles de ces prétraitements sont : $\mathrm{NaOH} 8$ à $12 \%$ massique/matière sèche, 30 à $60 \mathrm{~min}$ à $80-120^{\circ} \mathrm{C}$ [28]. Au cours du prétraitement, la lignine est presque en totalité solubilisée, ainsi qu'une partie des hémicelluloses (liqueurs noires).

Le produit prétraité présente une excellente susceptibilité à l'hydrolyse enzymatique, due à la solubilisation des hémicelluloses et des lignines, mais également à l'effet de gonflement par la soude des fibres cellulosiques les rendant plus accessibles à l'eau et aux agents d'hydrolyse. L'efficacité du traitement alcalin dépend de la nature du substrat et des conditions de traitement : il est plus efficace sur des résidus agricoles tels que les pailles que sur des coproduits du bois [26]. L'efficacité de l'hydrolyse enzymatique ultérieure de la cellulose varie avec la concentration de soude utilisée au cours du prétraitement. Après hydrolyse enzymatique, le taux de saccharification de la cellulose est inférieur à $30 \%$ pour une concentration en soude de 2 à $4 \%$, alors qu'il est compris entre 80 et $90 \%$ pour une concentration en soude de $10 \%$ [61]. D'après Hahn Hägerdal et al. [62], le prétraitement alcalin des pailles, pour des températures comprises entre 180 et $200^{\circ} \mathrm{C}$, permet d'atteindre des rendements d'hydrolyse enzymatique de la cellulose proche du rendement théorique maximum. Le prétraitement alcalin en présence de péroxyde d'hydrogène $\left(\mathrm{H}_{2} \mathrm{O}_{2}\right)$ d'un mélange de substrats ligneux ( $90 \%$ de bouleau et $10 \%$ d'érable), en utilisant $2,5 \%$ en poids d' $\mathrm{H}_{2} \mathrm{O}_{2}$ à $25^{\circ} \mathrm{C}$, a permis d'augmenter l'efficacité de cette hydrolyse enzymatique, d'autant plus que la durée de prétraitement était importante [63]. L'échantillon prétraité pendant $18 \mathrm{~h}$ a conduit à un rendement glucose de $68 \%$.

Cependant, l'efficacité du prétraitement alcalin s'accompagne toujours d'une perte de 30 à $35 \%$ de matière sèche initiale [28]. D'autre part, le coût actuel des réactifs chimiques tels que la soude pénalise fortement le procédé si l'extrait alcalin n'est pas valorisé. En effet, le recyclage de la soude est onéreux [64] et le résidu solide issu du prétraitement doit être lavé et neutralisé (essentiellement par lavage à l'eau sur filtre presse) avant hydrolyse enzymatique, ce qui engendre des coûts supplémentaires [28].

\subsubsection{Prétraitements à l'acide dilué}

Ces prétraitements sont réalisés par chauffage en présence d'acide sulfurique dilué, en proportion de 1 à $3 \%$ par rapport à la matière sèche lignocellulosique. Les températures et durées de traitement varient suivant les technologies utilisées : soit $200^{\circ} \mathrm{C}$ pour des temps de séjour inférieurs à $10 \mathrm{~s}$ (réacteur " piston "), soit 120 à $130^{\circ} \mathrm{C}$ pour des temps de séjour de l'ordre de $30 \mathrm{~min}$ (réacteur à percolation) [28]. Ces traitements ont pour effet d'augmenter la surface de la cellulose accessible aux enzymes, grâce à l'extraction de la fraction hémicellulosique, mais ils ont peu d'effet sur l'indice de cristallinité [53]. Ces procédés conduisent à de bons rendements d'hydrolyse des hémicelluloses en sucres monomères, et cela améliore la digestibilité enzymatique de la cellulose $[19,65,66]$. Cette technique est efficace sur une gamme très variée de substrats (feuillus, plantes herbacées, coproduits agricoles).

Les rendements d'hydrolyse enzymatique de la cellulose de plusieurs produits prétraités à l'acide sulfurique dilué sont supérieurs à $90 \%$ [19]. Comme dans le cas de l'explosion à la vapeur, l'augmentation de la température augmente la digestibilité enzymatique de la cellulose, mais également les pertes en matière sèche [53]. Le rendement d'hydrolyse de la cellulose passe de $98 \%$ à $45 \%$ lorsqu'on descend la température de $220^{\circ} \mathrm{C}$ à $180^{\circ} \mathrm{C}$, pour une concentration en $\mathrm{H}_{2} \mathrm{SO}_{4}$ constante de $1 \%[53,63]$.

Concernant la fraction hémicellulosique, Grohmann et al. [67, 68], Grohmann et Torget [69], Torget et al. [65, 66, 70] ont obtenu des rendements en xylose proches de $80 \%$ du rendement théorique. Les rendements d'hydrolyse des hémicelluloses varient également avec la température, mais pour la plupart des substrats ligneux à courte rotation et les plantes herbacées, l'hydrolyse complète des hémicelluloses se produit en 5-10 min à $160^{\circ} \mathrm{C}$, ou 30-60 min à $140^{\circ} \mathrm{C}$ [19].

Torget et al. [71] ont développé un procédé utilisant deux réacteurs à percolation fonctionnant à deux températures différentes. En effet, de faibles températures $\left(150-174{ }^{\circ} \mathrm{C}\right)$ sont appliquées pour solubiliser et hydrolyser la fraction la plus accessible des xylanes, et de fortes températures $\left(180^{\circ}\right.$ $204^{\circ} \mathrm{C}$ ) pour les xylanes plus résistants. De plus, les deux réacteurs fonctionnent à contre-courant. Dans le cas de sciures de peuplier jaune, cette technique a permis de récupérer $97 \%$ du xylose, et la digestibilité enzymatique de la cellulose était comprise entre 84 et $91 \%$ du rendement théorique.

À quelques exceptions près [68, 72], les équipes ayant travaillé sur l'hydrolyse à l'acide dilué utilisaient des concentrations en matières solides faibles, inférieures à $10 \%$. Pourtant, une concentration plus élevée en matières solides permet de diminuer la taille du réacteur et de réduire la consommation de vapeur. Kadam et Teh-an-Hsu [73] ont développé un réacteur de 130 L (réacteur polyphase R fourni par Littleford Day Inc.) pourvu d'un mélangeur permettant de fonctionner avec une concentration en biomasse solide supérieure à $40 \%$, et 
adapté aux transferts de masse et de chaleur en milieux visqueux. Ils ont testé leur procédé sur un peuplier hybride DN34 à 4,5\% d'humidité initiale. La température et le temps de traitement étaient fixés respectivement à $150{ }^{\circ} \mathrm{C}$ et $30 \mathrm{~min}$, la concentration acide comprise entre 0,7 et $3,7 \%$ (exprimés par rapport à la phase liquide). Les résultats obtenus montrent un taux de récupération du xylose maximal (hydrolyse complète des xylanes avec peu de furfural formé), et une diminution de moitié de la consommation d'acide. Après $150 \mathrm{~h}$ de SFS (saccharification et fermentation simultanées), le rendement en éthanol était compris entre 70 et $80 \%$ du rendement théorique maximum.

L'un des avantages des procédés à l'acide dilué est l'obtention de rendements d'hydrolyse élevés concernant la fraction hémicellulosique. Alors que l'explosion à la vapeur n'hydrolyse que 30 à $50 \%$ des xylanes en xylose, les rendements en xylose sont de l'ordre de 80 à $90 \%$ lorsqu'on utilise un prétraitement à l'acide dilué. De plus, ce traitement améliore très nettement la digestibilité enzymatique de la cellulose.

Cependant, les sucres étant instables en milieu acide et chaud, ils peuvent parfois se dégrader en composés furaniques inhibant les fermentations [28]. Les procédés opérant à température modérée réduisent la décomposition des sucres [32], mais la digestibilité enzymatique de la cellulose est alors diminuée.

D'autre part, il y a nécessité d'un post-traitement de neutralisation du résidu acide à la chaux éteinte, aboutissant à la formation de sulfate de calcium, posant des problèmes de récupération, et ayant une faible valeur ajoutée [19].

D'autres acides ont également été étudiés : acide nitrique dilué [74, 75], acide phosphorique dilué [76], acide paracétique [77], mais les performances ne sont pas supérieures. L'acide phosphorique présenterait toutefois un intérêt, dans la mesure où le phosphore résiduel peut être utilisé comme nutriment par le micro-organisme fermentaire.

\subsubsection{Prétraitement Afex}

Ce procédé consiste en un traitement de la matière lignocellulosique avec de l'ammoniaque liquide sous pression modérée (15 bar), suivi par une brusque décompression dans le but d'évaporer l'ammoniac et d'exploser le substrat. Cette technique est une variante de l'explosion à la vapeur, mais dans des conditions de températures nettement plus faibles grâce à l'emploi d'ammoniac. La température moyenne dans le réacteur est comprise entre 50 et $80^{\circ} \mathrm{C}$, minimisant ainsi la formation de composés inhibiteurs [53]. L'ammoniac résiduel peut être utilisé comme nutriment par le micro-organisme fermentaire. Les matières lignocellulosiques traitées à partir de ce procédé sont surtout des substrats agricoles : luzerne, paille de blé, paille d'orge, bagasse, etc. [78], avec lesquels les rendements d'hydrolyse enzymatique de la cellulose sont compris entre 80 et $90 \%$ du rendement théorique [79].
Cependant, il subsiste certains inconvénients liés à l'utilisation de cette technique. Les concentrations élevées en ammoniac, avec nécessité de le recycler plusieurs fois par compression, et les pertes non négligeables d'ammoniac sont préjudiciables sur le plan économique [19]. Ce type de traitement est inefficace sur des substrats ligneux [26], et les rendements d'hydrolyse de la fraction hémicellulosique sont généralement faibles. Les rendements d'hydrolyse enzymatique de la cellulose n'ont jamais dépassé $50 \%$ du rendement théorique sur des copeaux de bois de peuplier [80], ou $40 \%$ sur des substrats provenant de déchets de papier [78]. Enfin, l'ammoniac est un produit dangereux, et les installations devront être parfaitement étanches afin d'éviter toute perte de produits.

\subsubsection{Prétraitement au $\mathrm{CO}_{2}$}

Le principe reste sensiblement identique au traitement Afex, en substituant l'ammoniac par du $\mathrm{CO}_{2}$. Dale et Moreira [81] ont testé cette technique sur la luzerne $(5,58 \mathrm{MPa}$ de pression, et en présence de $4 \mathrm{~g}$ de $\mathrm{CO}_{2} / \mathrm{g}$ de fibre). Après $24 \mathrm{~h}$ d'hydrolyse enzymatique, $75 \%$ du rendement théorique était atteint [81]. Cependant, cette technique n'a jamais connu de développement.

\subsection{Prétraitements biologiques}

Les prétraitements biologiques mettent en œuvre certains basidiomycètes tels que Phanerochaete chrysosporium, qui peuvent dans certaines conditions, dégrader activement la lignine. Des souches mutantes dépourvues de cellulases ont été obtenues et proposées pour effectuer une délignification biologique des lignocelluloses [28]. La lenteur du processus et les difficultés de contrôle des conditions opératoires rendent peu probables l'extrapolation de ce type de procédé [28]. Les équipes ayant travaillé sur ce sujet sont nombreuses : Kohlman et al. [52]; Basaglia et al. [82]; Ghosh et Singh [83] ; Eriksson [84], etc. La plupart des essais ont été réalisés à l'échelle du laboratoire.

\subsection{Procédé 0 rganosolv}

Le principe de cette technique, venant de l'industrie papetière, consiste à rajouter un solvant organique (méthanol ou éthanol) au procédé de prétraitement, afin de dissoudre et d'extraire la fraction lignine. Ce prétraitement aboutit à la solubilisation de la lignine et de la fraction hémicellulosique, et conduit à un résidu solide constitué essentiellement de cellulose. Le solvant organique est par la suite extrait par évaporation, puis recyclé. La lignine précipitée est récupérée par simple filtration ou centrifugation. En général, le procédé Organosolv permet d'obtenir de bons rendements de récupération des sucres [85]. Le principal inconvénient de cette technique demeure le coût élevé du solvant. La nécessité d'un recyclage de $100 \%$ condamne économiquement ce type de procédé. 
On peut également citer les procédés [86, 87] utilisant des liquides supercritiques pour solubiliser la lignine. Mais ces procédés sont difficiles à mettre en œuvre, et restent très coûteux en réactifs chimiques et en investissements.

\subsection{Explosion à la vapeur avec catalyse}

Lorsque l'explosion à la vapeur est appliquée sur un substrat préalablement acidifié avec $\mathrm{l}^{\prime} \mathrm{H}_{2} \mathrm{SO}_{4}$, elle conduit à une solubilisation et une hydrolyse totale des hémicelluloses en leurs monomères, sans dégradation en furfural. En outre, la susceptibilité de la cellulose à l'hydrolyse enzymatique est améliorée [88, 89]. L'utilisation d'un catalyseur acide permet de diminuer la température du procédé $\left(150\right.$ à $200{ }^{\circ} \mathrm{C}$ contre $250^{\circ} \mathrm{C}$ pour l'explosion à la vapeur sans catalyseur), et ainsi de minimiser la formation de composés de dégradation. L'imprégnation à l'acide de feuillus suivie d'une explosion à la vapeur a été longuement étudiée par Ascaf [19, 66, 67, 90].

Les études menées par l'Ascaf [91] sur la plate-forme de Soustons (France) ont confirmé que l'imprégnation acide améliore l'hydrolyse des hémicelluloses, permettant ainsi de récupérer une solution enrichie en xylose. Sur de la paille de blé (15 à 18 bar pendant $2 \mathrm{~min}$ ), l'hydrolyse des hémicelluloses et l'hydrolyse enzymatique de la cellulose (10 UPF, $24 \mathrm{~h}$ ) après prétraitement étaient quasiment complètes. Cependant, une trop grande sévérité du traitement entraîne une perte non négligeable en pentoses [34]. Sur des substrats plus résistants (peuplier), l'imprégnation à l'acide suivie de l'explosion à la vapeur (16 bar, $150 \mathrm{~s})$ a permis de récupérer $90 \%$ du glucose potentiel et $60 \%$ des pentoses. Les pertes de matières sèches ne dépassaient pas $10 \%$ et correspondaient essentiellement à du furfural et de l'acide acétique [37].

Plusieurs équipes ont également travaillé sur l'explosion vapeur en présence de $\mathrm{SO}_{2}$ comme agent d'hydrolyse [22, 23, 33, 92-98]. Outre le fait qu'il conduise à des rendements en xylose élevés, ce prétraitement serait l'un des seuls efficaces pour la préparation des substrats de type bois de résineux [26]. À partir d'un résineux (Pinus radiata), cette technique a permis d'hydrolyser $82 \%$ de la cellulose en glucose, après $72 \mathrm{~h}$ d'hydrolyse enzymatique [33]. Comme l' $\mathrm{H}_{2} \mathrm{SO}_{4}$, le $\mathrm{SO}_{2}$ permet également de diminuer les temps de contact et la température du prétraitement par explosion à la vapeur, limitant ainsi la dégradation des pentoses [22]. $\mathrm{Le} \mathrm{SO}_{2}$ pourrait être préféré à l' $\mathrm{H}_{2} \mathrm{SO}_{4}$ car ce réactif gazeux pénètre plus facilement et plus rapidement dans la matrice lignocellulosique [20]. Cependant, le $\mathrm{SO}_{2}$ n'est pas l'agent d'hydrolyse : il se transforme en $\mathrm{H}_{2} \mathrm{SO}_{4}$ au contact de l'eau contenue dans le végétal. Dès lors, le caractère non corrosif de cet agent d'hydrolyse reste à valider. D'autre part, une partie du réactif peut être perdue par évaporation et dans l'eau de lavage. D'après Gregg et Saddler [89], seule la moitié du $\mathrm{SO}_{2}$ utilisé est active. Enfin, la toxicité de l'anhydride sulfureux rend son utilisation industrielle délicate, bien que cette technique ait déjà connu un développement à l'échelle pilote [94].

\subsection{Technologie bi-vis}

La technologie bi-vis permet de combiner des actions thermique, mécanique et chimique avec une intensité relative variable. N'Dyayes et al. [99] ont étudié l'extraction alcaline des hémicelluloses par cette technologie dans des conditions douces (températures de 25 à $70^{\circ} \mathrm{C}$ ). Le fractionnement des matériaux lignocellulosiques par la technologie bi-vis ouvre des perspectives intéressantes :

- le travail thermo-mécanico-chimique doit favoriser l'hydrolyse de la cellulose ;

- l'hydrolyse acide des hémicelluloses extraites s'avère très facile et rapide. Les temps de contact sont réduits (10-20 min), pour des températures de $120-130^{\circ} \mathrm{C}$, et les rendements en xylose sont supérieurs à $70 \%$ du rendement théorique pour une quantité d'acide inférieure à $0,3 \mathrm{~g} / \mathrm{g}$ d'extrait.

Qiabi et al. [100] ont par ailleurs testé l'hydrolyse acide des hémicelluloses directement dans la matière végétale, selon les conditions opératoires suivantes :

- teneur acide $=0,5$ à $2 \%$;

- température réacteur $=120$ à $140{ }^{\circ} \mathrm{C}$;

- temps de réaction $=15-20 \mathrm{~min}$.

La simulation en batch dans un réacteur de type autoclave a permis d'atteindre des rendements en xylose de 85-90\% avec des substrats variés (sorgho, paille de blé, rafles de maïs).

Ces auteurs n'ont pas encore testé la susceptibilité à l'hydrolyse enzymatique du résidu cellulosique, mais le travail de l'extrudeur (broyage) associé à l'effet de l'agent chimique ne peuvent avoir qu'un effet très favorable sur la digestibilité enzymatique du substrat.

\section{9 Études comparatives entre différents prétraitements}

Ces études permettent des comparaisons plus objectives entre les différents prétaitements, étant donné que le substrat et les conditions expérimentales sont identiques pour les différents procédés testés.

Thompson et al. (63) ont comparé quatre types de prétraitements sur un substrat constitué d'un mélange de feuillus : traitement alcalin avec ajout de péroxyde d'hydrogène, traitements par un solvant organique (éthylènediamine), autohydrolyse par l'explosion à la vapeur et traitement à l'acide dilué. Le prétraitement à l'acide dilué a été le plus efficace pour augmenter la surface de la cellulose accessible aux enzymes.

Vlasenko et al. [101] ont comparé trois types de prétraitement : l'explosion à la vapeur avec catalyse acide, l'hydrolyse à acide dilué et le procédé Afex. Les expérimentations, sur paille de riz, ont été réalisées à l'échelle du laboratoire et les conditions expérimentales étaient identiques pour les trois prétraitements. Concernant le taux de récupération des pentoses, l'explosion vapeur avec catalyse acide (rendement 
de récupération $=79 \%$ ) était supérieure aux deux autres procédés $(60 \%$ pour le procédé d'hydrolyse à acide dilué, $15 \%$ pour le procédé Afex). Les rendements globaux de récupération des sucres (en tenant compte à la fois du prétraitement et de l'hydrolyse enzymatique) étaient également favorables à l'explosion vapeur avec catalyse acide.

\subsection{Conclusion}

Aucun des types de prétraitement décrits précédemment n'est entièrement satisfaisant. Généralement, les procédés se font à température élevée avec addition de produits chimiques, et génèrent en quantité plus ou moins importante des inhibiteurs posant des problèmes lors de l'étape de fermentation.

Les prétraitements mécaniques (broyage et irradiation) ont été décrits comme inefficaces, coûteux en énergie et économiquement non rentables. Les prétraitements alcalins sont lourds à mettre en œuvre, les consommations de produits chimiques pour la réaction et pour la neutralisation du produit traité sont onéreuses, les pollutions engendrées obligent à mettre en œuvre d'importants moyens de traitement et de récupération des réactifs. Le procédé Organosolv et autres procédés d'origine papetière sont trop onéreux en solvants, et leurs objectifs sont contraires à ceux recherchés en production d'éthanol carburant. Les techniques d'explosion avec l'ammoniac ou le $\mathrm{CO}_{2}$ ne sont pas plus efficaces comparativement à l'utilisation de produits classiques comme l'acide sulfurique, et l'emploi d'ammoniac peut être dangereux.

Le prétraitement à l'acide dilué à double étage (qui est l'objet de récents travaux au NREL) est une méthode attractive, améliorant la digestibilité enzymatique de la cellulose, permettant d'obtenir des rendements d'hydrolyse des hémicelluloses proches du maximum, tout en minimisant les réactions de dégradation des sucres (tableau 1). L'optimisation de ce procédé doit être poursuivie, notamment par des systèmes à contre-courant, ou par le développement de réacteurs pouvant fonctionner à forte concentration en matières solides.

La technologie bi-vis avec extraction alcaline pourrait s'avérer une méthode efficace pour améliorer la digestibilité enzymatique du substrat lignocellulosique, tout en permettant un fort taux de récupération des sucres issus de la fraction hémicellulosique.

Le procédé de thermohydrolyse semble également intéressant, bien qu'il n'ait connu aucune application industrielle à ce jour. Il permet des rendements d'hydrolyse élevés, et surtout il minimiserait la formation de produits de dégradation.

TABLEAU 1

Comparaison entre différentes méthodes de prétraitements

Comparison between different preatreatment methods

\begin{tabular}{|c|c|c|c|c|}
\hline & Technologie bi-vis & Explosion vapeur avec catalyse & Hydrolyse acide dilué & Thermohydrolyse \\
\hline Références & $\begin{array}{l}14 \\
97 \\
98\end{array}$ & $\begin{array}{l}30 \\
88 \\
89 \\
90 \\
93 \\
94\end{array}$ & $\begin{array}{l}66 \\
67 \\
68 \\
69 \\
71 \\
73\end{array}$ & $\begin{array}{l}45 \\
47 \\
48 \\
49 \\
50 \\
52\end{array}$ \\
\hline Types de substrats & Herbacés et feuillus & Herbacés, feuillus et résineux & Herbacés et feuillus & Herbacés et feuillus \\
\hline Conditions opératoires & $\begin{array}{c}\text { Continu } \\
120-130^{\circ} \mathrm{C} \\
10 \text { min à } 20 \mathrm{~min}\end{array}$ & $\begin{array}{l}\text { Batch ou continu } \\
160-200^{\circ} \mathrm{C} \\
1 \text { min à } 10 \mathrm{~min}\end{array}$ & $\begin{array}{l}\text { Batch ou continu } \\
150-180^{\circ} \mathrm{C} \\
5 \text { min à } 30 \mathrm{~min}\end{array}$ & $\begin{array}{c}\text { Batch } \\
170-230^{\circ} \mathrm{C} \\
5 \text { min à } 1 \mathrm{~h}\end{array}$ \\
\hline Consommation de réactifs & Oui & Oui & Oui & Non \\
\hline Récupération des pentoses & $>80 \%$ & $>80 \%$ & $>80 \%$ & $>80 \%$ \\
\hline Présence d'inhibiteurs & Peu & Oui si conditions sévères & Peu & Peu \\
\hline $\begin{array}{l}\text { Rendement hydrolyse } \\
\text { enzymatique de la cellulose }\end{array}$ & Peu testé & $>80 \%$ & $>90 \%$ & $>80 \%$ \\
\hline $\begin{array}{l}\text { Problèmes environnementaux } \\
\text { (génération de déchets) }\end{array}$ & Moyen & Moyen & Important & Faible \\
\hline État de l'art & $\begin{array}{l}\text { Perpectives } \\
\text { intéressantes, } \\
\text { améliorations } \\
\text { envisageables }\end{array}$ & $\begin{array}{c}\text { Nombreux pilotes } \\
\text { (français, canadiens et italiens) } \\
\text { améliorations possibles } \\
\text { sur la résistance des matériaux }\end{array}$ & $\begin{array}{c}\text { Pilotes récents }(N R E L) \\
\text { perspectives intéressantes : } \\
\text { contre-courant } \\
\text { forte concentration }\end{array}$ & $\begin{array}{c}\text { Pas de pilotes } \\
\text { mais regain } \\
\text { d'intérêt } \\
\text { ces dernières années }\end{array}$ \\
\hline
\end{tabular}


Le prétraitement par explosion à la vapeur apparaît comme une méthode attractive, bien qu'ancienne. Les procédés avec catalyse acide sont préférables car ils autorisent des rendements en xylose élevés, des températures dans le réacteur plus basses, et par conséquent, des produits de dégradation moindres.

La nature du prétraitement choisi dépendra également du substrat utilisé. Dans le cas de la paille de blé, les prétraitements alcalin et à la vapeur autour de $180-200^{\circ} \mathrm{C}$ donnent des bons rendements en glucose (80 à $95 \%$ du rendement théorique) comparés aux traitements mécaniques (18 à $38 \%$ ). Pour les coproduits ligneux (copeaux de bois, sciures), de bons rendements sont obtenus après traitement mécanique (70 à 75\%), alors que de faibles rendements sont obtenus après prétraitements à la vapeur (35\%) [64].

Enfin, il faut remarquer que la plupart des études ne mentionnent pas (ou peu) les méthodes préconisées pour extraire les sucres hydrolysés ou solubilisés au cours des opérations précédemment citées. Les technologies actuelles, utilisant des étapes de pressages et lavages intenses à l'eau, afin de récupérer le maximum de sucres, sont très coûteuses en investissement et en énergie, et elles auront un impact important sur l'économie du procédé.

\section{HYDROLYSE ENZYMATIQ UE}

L'hydrolyse enzymatique constitue une méthode spécifique, réalisée dans des conditions relativement douces $\left(50^{\circ} \mathrm{C}\right)$, et permettant des rendements d'hydrolyse supérieurs à ceux obtenus à partir des procédés chimiques. C'est la raison pour laquelle l'hydrolyse enzymatique a fait l'objet de nombreux travaux de recherche ces 10 dernières années, dans le but d'optimiser la production d'enzymes et leur efficacité, mais aussi d'améliorer les étapes de prétraitement. L'objectif est avant tout d'améliorer sa rentabilité économique, car elle constitue encore une méthode onéreuse, en raison notamment du coût élevé des enzymes et de la lenteur des réactions.

Un substrat aussi complexe que la biomasse lignocellulosique ne peut être hydrolysé totalement par une seule enzyme. L'hydrolyse enzymatique de la cellulose résulte de l'action synergique de trois types d'enzymes : les cellulases (endo 1,4 ß-glucanases et exo 1,4 ß-glucanases) qui hydrolysent les celluloses en cellobiose et les B-glucosidases qui hydrolysent le cellobiose en glucose.

\subsection{Production de cellulases}

Le champignon mésophile aérobie Trichoderma reesei et ses mutants ont été les plus étudiés pour la production de cellulases. Les cellulases de $T$. reesei présentent l'avantage de posséder les trois classes d'enzymes, bien qu'elles présentent souvent un déficit en B-glucosidase. De plus, elles sont inhibées rapidement par les produits formés (glucose et cellobiose).
La mise en œuvre à l'échelle industrielle de l'hydrolyse enzymatique requiert donc, d'une part, une préparation enzymatique équilibrée, et d'autre part, celle d'une technologie de mise en œuvre de ces enzymes. Les quantités de cellulases proposées sur le marché ont été, et sont encore beaucoup trop limitées et surtout d'un coût beaucoup trop élevé pour être utilisées dans des procédés de production d'éthanol. Des efforts importants de recherche et développement ont donc visé à développer des procédés de production de cellulases, intégrables au site de production d'éthanol et minimisant le coût d'accès à la source d'enzymes.

Jusqu'à la fin des années 1980, le principal obstacle lié à la production de cellulases était la faible productivité des micro-organismes [5]. Puis des progrès ont ensuite été apportés, à la fois par l'amélioration des techniques de fermentation, et par l'amélioration des souches productrices [102106]. Les meilleures productivités ont été obtenues par la mise en œuvre de technologie de cultures en fed batch alimentées par un substrat carboné soluble, le lactose, moins cher et plus facile à utiliser à l'échelle industrielle que les celluloses purifiées. Des productivités supérieures à $200 \mathrm{mg} / \mathrm{l} \cdot \mathrm{h}$ pour des concentrations finales supérieures à $40 \mathrm{~g} / \mathrm{l}$ de protéines ont été rapportées [91, 107, 108].

L'Ascaf, en utilisant le lactose comme substrat et un nouveau mutant de $T$. reesei développé par la société Cayla à Toulouse, a obtenu des productivités très élevées. La production de cellulases sur le site de Soustons se faisait en réacteur de $30 \mathrm{~m}^{3}$, et utilisait une technologie originale d'alimentation discontinue en lactose [38]. Les résultats obtenus ont confirmé les performances enregistrées en laboratoire et au pilote : plus de 20000 unités cellulases papier filtre et $30 \mathrm{~g}$ de protéines enzymatiques extracellulaires produites par litre de milieu [109]. Ces performances placent $T$. reesei, parmi les meilleures souches productrices de protéines extracellulaires en conditions industrielles.

Les quantités élevées de protéines excrétées par ces souches mutantes laissent peu d'espoir d'amélioration supplémentaire sur ce critère. Les efforts devront désormais porter sur l'amélioration qualitative de l'activité de ces enzymes: meilleure activité spécifique (mesurée sur papier filtre), meilleure stabilité et insensibilité au rétrocontrôle. Actuellement, l'activité spécifique des cellulases est de l'ordre de 0,6 IU (International Unit)/mg de protéine contre $100 \mathrm{IU} / \mathrm{mg}$ pour les amylases. De même, bien que la faiblesse en activité cellobiase ait pu être corrigée par l'amélioration génétique des souches productrices, la composition du cocktail enzymatique doit encore être améliorée.

\subsection{Technologie de l'hydrolyse}

Réduire le coût de consommation des cellulases peut également s'obtenir par une réduction de la quantité consommée, en optimisant la technologie d'hydrolyse et/ou en cherchant à recycler les activités enzymatiques récupérables 
après une opération d'hydrolyse. La technologie d'hydrolyse utilisée le plus couramment est la simple mise en contact d'une suspension de substrat lignocellulosique avec la solution enzymatique, et le maintien de la température, du $\mathrm{pH}$ et de l'homogénéité du mélange au cours de l'opération. Une fois déterminées les conditions optimales de $\mathrm{pH}$ et de température, les possibilités d'optimisation sont particulièrement limitées.

Les tentatives de recyclage des activités enzymatiques récupérables en fin d'hydrolyse ont été effectuées par plusieurs équipes [110-117]. Les techniques de recyclage se heurtent aux propriétés d'adsorption des enzymes sur la cellulose résiduelle et probablement sur la lignine [118-120].

Les résultats rapportés sont contradictoires, certaines équipes préconisant la récupération des activités à partir de la phase liquide obtenue par percolation de cette dernière sur un substrat frais [109]. D'autres préconisent la récupération des activités à partir du résidu solide de l'hydrolyse, par mélange de ce résidu à une charge de substrat frais $[112,117]$. De plus l'évaluation économique de ce recyclage n'a pas été effectuée, et il est difficile aujourd'hui de décider si les quantités d'enzymes récupérées compenseront le coût en investissements supplémentaires (pompes et séparateurs) nécessaires à la mise en œuvre de cette technologie.

\subsection{Conclusion}

L'inconvénient majeur de l'hydrolyse enzymatique réside dans le coût des enzymes utilisées, qui demeure élevé. L'objectif des nouveaux programmes de recherche est d'améliorer l'efficacité de la préparation enzymatique, tout en maintenant son coût de production constant. Deux voies sont possibles : l'amélioration génétique des souches productrices et la SFS. Ce dernier point sera abordé dans le chapitre sur la fermentation alcoolique. Il pourrait également être très utile "d'adapter" les enzymes aux produits prétraités, plutôt que d'optimiser les prétraitements à l'activité des enzymes.

\section{FERMENTATION ÉTHAN O LIQ UE DES SUCRES}

Les sucres obtenus par hydrolyse de la biomasse lignocellulosique sont des pentoses (xylose et arabinose principalement), des disaccharides (cellobiose) et du glucose. Ce dernier est facilement transformé en éthanol par la levure $S$. cerevisiae utilisée par l'ensemble des industries de fermentation alcoolique. Actuellement, aucun autre micro-organisme n'atteint ses performances sur glucose en conditions non stériles, à savoir un rendement de l'ordre de 0,47 g d'éthanol par g de glucose,une productivité supérieure ou égale à $5 \mathrm{~g} / \mathrm{l} \cdot \mathrm{h}$, et des concentrations finales en éthanol voisines de $10 \%$ en volume. S. cerevisiae présente de nombreux atouts supplémentaires résultant de nombreuses années de sélection: résistance à l'éthanol, mise en œuvre industrielle aisée, etc. La fermentation du glucose ne sera donc pas abordée ici, sauf dans le cas particulier de la SFS.
Par contre, les pentoses sont rarement fermentés par les micro-organismes et, lorsqu'ils le sont, les performances sont médiocres. Ces dernières années, beaucoup de travaux ont porté sur la recherche et/ou l'amélioration des souches fermentant activement les pentoses en éthanol. Pour ce faire, quatre types de micro-organismes ont été étudiés : les levures fermentant naturellement les pentoses, des souches recombinées de $S$. cerevisiae, des bactéries thermophiles ou mésophiles utilisant les pentoses. La fermentation du cellobiose sera ensuite abordée rapidement. La dernière partie sera consacrée à l'étude des différentes technologies possibles pour fermenter les hydrolysats lignocellulosiques.

\subsection{Fermentation des pentoses}

\subsubsection{Levures capables de fermenter les pentoses}

Au début des années 1980, d'importantes recherches ont été entreprises afin d'isoler des souches capables de fermenter naturellement le xylose en éthanol [2, 121, 122]. Trois espèces de levure ont été identifiées comme étant les plus efficaces : Pichia stipitis, Candida shehatae et Pachysolen tannophilus. Cependant, les performances fermentaires obtenues par ces micro-organismes restent faibles, comparativement à celles obtenues par $S$. cerevisiae sur glucose (tableau 2).

De plus, les contraintes associées à l'utilisation de ces souches se sont révélées être un handicap important. La fermentation alcoolique du xylose n'est possible qu'en présence d'une faible quantité d'oxygène [123], qui doit être rigoureusement ajustée. En effet, un excès d'oxygène favorise la production cellulaire au détriment de la production d'éthanol [124].

D'autre part, les micro-organismes utilisés sont particulièrement sensibles à l'éthanol $[62,123]$ et sont inhibés à partir d'une concentration de l'ordre de 3 à $5 \%$ (en poids). Différentes voies ont été expérimentées afin de s'affranchir de ce problème : sélection de mutants résistants [125], fusion de protoplastes [126], extraction continue de l'éthanol. Mais aucune n'a réellement abouti. Ces levures sont aussi particulièrement sensibles aux inhibiteurs présents dans les hydrolysats tels que l'acide acétique [127].

Malgré les nombreuses études réalisées avec ces levures, celles-ci possèdent toujours de nombreux points faibles et leurs performances fermentaires n'ont jamais été significativement améliorées.

\subsubsection{Saccharomyces cerevisiae}

Bien qu'étant incapable de fermenter le xylose en éthanol, $S$. cerevisiae présente la propriété de fermenter le xylulose obtenu par isomérisation du xylose (fig. 4). Ainsi, plusieurs approches ont été développées afin d'utiliser $S$. cerevisiae pour fermenter le xylose :

- Introduction chez $S$. cerevisiae des gènes bactériens permettant la transformation du xylose en xylulose (codant 
TABLEAU 2

Performances fermentaires des levures sur xylose

Performance of pentose fermenting yeasts

\begin{tabular}{|c|c|c|c|c|c|c|}
\hline & Xylose (g/l) & Rendement $^{\mathrm{a}}(\mathrm{g} / \mathrm{g})$ & 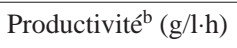 & Éthanolc $^{\mathrm{c}}(\mathrm{g} / \mathrm{l})$ & Type de milieu & Références \\
\hline C.sh. (ATCC22984) & 57 & 0,39 & 0,56 & 22,3 & complexe & [128] \\
\hline C.sh. (CSIR-57D11) & 50 & 0,42 & 0,48 & 20 & complexe & [122] \\
\hline C. sh. (CSIR-Y492) & 90 & 0,29 & 1,31 & 26,2 & complexe & [129] \\
\hline C. sh. (CSIR-Y492) & - & 0,29 & 0,65 & 26 & complexe & [129] \\
\hline C. sh. & - & - & 1,17 & 56 & - & [130] \\
\hline C. sh. (CBS-2279) & 20 & 0,37 & 0,47 & - & - & [131] \\
\hline C. sh. (NRRLY12856) & 50 & 0,45 & 0,29 & 24 & complexe & [132] \\
\hline P. st. (CBS 5776) & 50 & 0,45 & 0,34 & 22,3 & complexe & [133] \\
\hline P. st. (CSIR-Y633) & 50 & 0,43 & 0,45 & 21,5 & complexe & [122] \\
\hline P. st. (NRRLY-7124) & 50 & 0,42 & 0,60 & 21 & - & [134] \\
\hline P. st. & 50 & 0,41 & 0,28 & 20 & - & [132] \\
\hline P. st. (NRRLY-7124) & 150 & 0,39 & 0,28 & 56 & complexe & [132] \\
\hline P. st. (CBS 7126) & 20 & 0,39 & 0,53 & - & - & [131] \\
\hline P. st. (NRRLY-7124) & 50 & 0,43 & 0,18 & - & - & [135] \\
\hline P. ta. (NRRLY-2460) & - & 0,21 & 0,12 & - & complexe & [136] \\
\hline P. ta. (NRRLY-2460) & 20 & 0,31 & 0,06 & 6,2 & - & [137] \\
\hline P. ta. (RL171) & 50 & 0,28 & 0,28 & 13,8 & - & [138] \\
\hline P. ta. (NRRLY-2460) & 50 & 0,32 & 0,16 & 16 & complexe & [139] \\
\hline P. ta. (NRRLY-2460) & 100 & 0,25 & 0,13 & 24 & complexe & [139] \\
\hline
\end{tabular}

a : rendement basé sur le xylose consommé

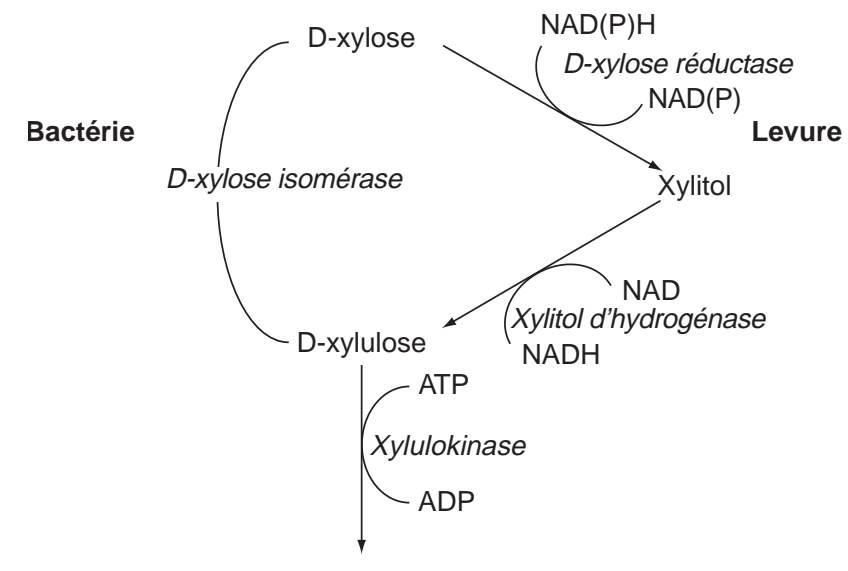

D-xylulose-5-P

Figure 4

Conversion du xylose en xylulose-5-phosphate chez les bactéries et les levures (d'après McMillan, 1996).

Conversion of xylose to xylulose-5-phosphate (by McMillan, 1996).

pour la xylose isomérase). Cette technique a connu peu de succès, à cause de l'expression très réduite de la protéine clonée [140-142]. De meilleures performances ont été obtenues quand le même gène est inséré chez Sch. pombe [143] (tableau 3).

\section{TABLEAU 3}

Performances fermentaires de $S$. cerevisiae. et $S c h$. pombe sur xylose après recombinaison pour les gènes codant pour la xylose isomérase (XI)

$X y l o s e$ fermentation performance by recombinant $S$. cerevisiae and Sch. pombe containing xylose isomerase (XI) genes

\begin{tabular}{l|c|c|c|c|c}
\hline & $\begin{array}{c}\text { Xylose } \\
(\mathrm{g} / \mathrm{l})\end{array}$ & $\begin{array}{c}\mathrm{Rdt}^{\mathrm{a}} \\
(\mathrm{g} / \mathrm{g})\end{array}$ & $\begin{array}{c}\text { Prod. }^{\mathrm{b}} \\
(\mathrm{g} / \mathrm{l} \cdot \mathrm{h})\end{array}$ & $\begin{array}{c}\text { Éthanol }^{\mathrm{c}} \\
(\mathrm{g} / \mathrm{l})\end{array}$ & Références \\
\hline Sch. pombe & 50 & 0,15 & 0,02 & 7,5 & {$[143]$} \\
Sch. pombe & $50^{\mathrm{d}}$ & 0,42 & 0,19 & 21 & {$[143]$} \\
S. cerevisiae & 30 & 0,05 & 0,01 & 1,4 & {$[144]$} \\
\hline
\end{tabular}

a : rendement basé sur le xylose consommé

$\mathrm{b}$ : productivité maximale

c : concentration maximale

$\mathrm{d}: 50 \mathrm{~g} / \mathrm{l}$ de xylose + extrait de levure

- Isomérisation enzymatique du xylose en xylulose à l'aide d'une isomérase ajoutée au milieu, sachant que $S$. cerevisiae pourra réaliser la fermentation alcoolique du xylulose produit. Des rendements supérieurs à $90 \%$ du rendement théorique ont été rapportés (tableau 4), mais avec une vitesse de fermentation très lente [145]. Des performances similaires ont été obtenues en substituant $S$. cerevisiae par Sch. pombe. Cependant, ce procédé SFIX (Simultaneous Fermentation and Isomerisation of Xylose) est limité par le prix élevé de la xylose isomérase commerciale. De plus, l'enzyme n'est pas très stable en présence d'hydrolysats 
TABLEAU 4

Performances fermentaires de $S$. cerevisiae et $S c h$. pombe sur xylulose après isomérisation enzymatique du xylose

Xylulose fermentation performance by recombinant $S$. cerevisiae and Sch. pombe

\begin{tabular}{|c|c|c|c|c|c|c|}
\hline & Types d'enzymes & Xylose $(\mathrm{g} / \mathrm{l})$ & Rendement $^{\mathrm{a}}(\mathrm{g} / \mathrm{g})$ & Productivitéb $^{\mathrm{b}}(\mathrm{g} / \mathrm{l} \cdot \mathrm{h})$ & Éthanolc $^{\mathrm{c}}(\mathrm{g} / \mathrm{l})$ & Références \\
\hline S. cer. (ATCC24860) & Actinoplanes & 60 & 0,30 & 0,38 & 18,1 & {$[145]$} \\
\hline S. cer. (ATCC24860) & Streptomyces & 60 & 0,32 & 0,41 & 19,5 & [145] \\
\hline S. cer. (bakers'yeast) & Optisweet-P & 48 & 0,50 & 1 & 24 & [146] \\
\hline S. cer. (bakers'yeast) & Optisweet-P & 175 & 0,34 & 1,30 & 60 & [146] \\
\hline S. pombe (NRRLY16) & Sweetzyme Q & 40 & 0,37 & 0,37 & 14,8 & [147] \\
\hline S. pombe (NRRLY16) & Sweetzyme Q & 60 & 0,34 & 0,67 & 20,4 & [147] \\
\hline S. pombe (NRRLY16) & Sweetzyme Q & 100 & 0,31 & 0,64 & 31 & [147] \\
\hline S. pombe (NRRLY16) & Sweetzyme Q & 160 & 0,31 & 0,48 & 49,6 & [147] \\
\hline
\end{tabular}

a : rendement basé sur le xylose consommé

$\mathrm{b}$ : productivité maximale

c : concentration maximale.

cellulosiques [62], et il reste le problème de l'incompatibilité entre les conditions optimales de l'isomérisation $(\mathrm{pH} 7)$ et de la fermentation ( $\mathrm{pH} 4)$.

- Introduction chez S. cerevisiae les gènes levuriens permettant l'assimilation du xylose et codant pour la XR (xylose réductase), la XDH (xylose déshydrogénase) et la $\mathrm{XK}$ (xylulokinase). Initialement, la recombinaison portait seulement sur les deux gènes XR et XDH [148, 149], mais les rendements D'éthanol étaient faibles suite à l'accumulation de xylitol. Ho et Tsao [150], en recombinant $S$. cerevisiae pour les 3 gènes (XR, $\mathrm{XDH}, \mathrm{XK})$, ont obtenu des résultats particulièrement prometteurs (tableau 5).

\section{TABLEAU 5}

Performances de $S$. cerevisiae sur xylose après recombinaison pour les gènes codant pour la xylose reductase $(\mathrm{XR})$, la xylose déshydrogénase (XDH) et la xylulokinase (XK)

$X y l o s e$ fermentation performance by recombinant $S$. cerevisiae containing xylose reductase $(\mathrm{XR})$, xylose dehydrogenase $(\mathrm{XDH})$ and xylulokinase $(X K)$ genes

\begin{tabular}{l|c|c|c|c|c}
\hline $\begin{array}{c}\text { Gènes } \\
\text { recombinés }\end{array}$ & $\begin{array}{c}\text { Xylose } \\
(\mathrm{g} / \mathrm{l})\end{array}$ & $\begin{array}{c}\mathrm{Rdt}^{\mathrm{a}} \\
(\mathrm{g} / \mathrm{g})\end{array}$ & $\begin{array}{c}\text { Prod. }^{\mathrm{b}} \\
(\mathrm{g} / \mathrm{l} \cdot \mathrm{h})\end{array}$ & $\begin{array}{c}\text { Éthanol }^{\mathrm{c}} \\
(\mathrm{g} / \mathrm{l})\end{array}$ & Références \\
\hline XR & 20 & - & 0,29 & - & {$[151]$} \\
XR et XDH & 20 & 0,037 & 0,02 & 0,74 & {$[152]$} \\
XR, XDH, XK & $\mathrm{d}$ & 0,43 & - & 47 & {$[150]$} \\
\hline
\end{tabular}

a : rendement basé sur le xylose consommé

$\mathrm{b}$ : productivité maximale

$\mathrm{c}$ : concentration maximale

d : mélange xylose/glucose (50/50)

Parmi les trois stratégies que nous venons de décrire, celle développée par Ho et Tsao [150] portant sur la recombinaison de $S$. cerevisiae avec 3 gènes semble la plus attractive. Toutefois, ces travaux sont récents, et l'utilisation sur hydrolysats de cette souche recombinée n'a pas encore été expérimentée. Il paraît difficile de prédire à l'heure actuelle quel sera le comportement de cette souche sur un milieu beaucoup moins favorable qu'un milieu synthétique.

\subsubsection{Bactéries thermophiles}

Plusieurs espèces de bactéries thermophiles sont capables de réaliser la fermentation alcoolique du xylose. Leur utilisation à température élevée peut présenter deux avantages : la diminution des risques de contamination et le couplage possible à des techniques d'extraction continue de l'éthanol comme la pervaporation.

Des rendements proches de $90 \%$ du rendement théorique ont été obtenus avec Thermoanaerobacter ethanolicus [153155] (tableau 6), mais à partir d'une faible concentration initiale en xylose. Clostridium thermohydrosulfuricum a été aussi largement étudié en culture continue dans le cadre du procédé DMC (Direct Microbial Conversion). Mais la fermentation s'accompagnait systématiquement d'une production non négligeable d'acétate [156]. Des cocultures entre $\mathrm{Cl}$. thermohydrosulfuricum et $\mathrm{Cl}$. thermocellum [157] ou $\mathrm{Cl}$. thermocellum et $\mathrm{T}$. ethanolicus [158] ont également été expérimentées.

Le procédé Agrol utilise des bactéries thermophiles modifiées génétiquement, qui ont la capacité de produire très rapidement de l'éthanol à partir de tous les sucres présents dans les hydrolysats de biomasse [159]. La bactérie utilisée est un mutant de Bacillus stearothermophilus ayant perdu l'activité LDH (lactate déshydrogénase). Cependant, ce procédé ne semble fonctionner que pour de faibles concentrations en sucres (inférieures à $2 \%$ ). D'autre part, la complexité du procédé, le risque de réversion des souches mutées et les conditions de stérilité rendent difficiles son application à l'échelle industrielle.

L'utilisation de bactéries thermophiles pour la fermentation des pentoses semble difficilement envisageable. En effet, elles présentent de faibles rendements d'éthanol dus à la production de divers coproduits. Leur faible tolérance à l'éthanol implique l'emploi de techniques complexes de fermentation à faible concentration en sucres. Leur forte sensibilité aux inhibiteurs, et l'ajout nécessaire de facteurs de croissance dans le milieu de fermentation sont aussi des inconvénients majeurs. 
TABLEAU 6

Performances fermentaires obtenues avec bactéries thermophiles sur xylose Xylose fermentation performance by thermophilic bacteria

\begin{tabular}{|c|c|c|c|c|c|c|}
\hline & Types de milieu & Xylose $(\mathrm{g} / \mathrm{l})$ & Rendement $^{\mathrm{a}}(\mathrm{g} / \mathrm{g})$ & 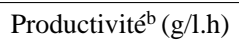 & Ethanol $^{\mathrm{c}}$ & Références \\
\hline T.ethanolicus & Complexe & 10 & 0,50 & 0,12 & 5,1 & {$[153]$} \\
\hline T.ethanolicus & Complexe & 4 & 0,42 & 0,50 & 1,7 & [154 et 155$]$ \\
\hline T. ethanolicus & Complexe & 20 & 0,25 & - & - & {$[160]$} \\
\hline Cl. thermosaccharolyticum & Complexe & 6 & 0,30 & 0,13 & 1,8 & {$[161]$} \\
\hline Cl. thermosaccharolyticum & Complexe & 35 & 0,37 & 1,03 & 12,8 & [162] \\
\hline Cl. thermohydrosulfuricum & Complexe & - & 0,43 & - & - & {$[157]$} \\
\hline B. stearothermophilus & $\begin{array}{c}\text { Complexe } \\
\text { Recyclage partiel } \\
\text { des cellules }\end{array}$ & $10^{\mathrm{d}}$ & $\begin{array}{l}0,40 \text { (xyl) } \\
0,47 \text { (glc) }\end{array}$ & $\begin{array}{l}0,45 \text { (xyl) } \\
0,74(\mathrm{glc})\end{array}$ & - & {$[159]$} \\
\hline
\end{tabular}

a : rendement basé sur le xylose consommé

$\mathrm{b}$ : productivité maximale

c : concentration maximale

$\mathrm{d}: 10 \mathrm{~g} / \mathrm{l}$ de glucose $+10 \mathrm{~g} / \mathrm{l}$ de xylose

\subsubsection{Bactéries mésophiles}

Certaines bactéries mésophiles ne peuvent pas fermenter les pentoses, mais sont capables de performances fermentaires élevées sur glucose, grâce à une voie d'assimilation efficace (voie d'Entner Doudoroff) telles que Zymomonas mobilis. L'équipe du NREL [163] a introduit chez Z. mobilis 4 gènes d'E. coli codant pour xylose isomérase (XI), xylulokinase (XK), transkétolase et transaldolase. La souche recombinée est alors capable de croître sur xylose comme unique source de carbone, avec des rendements d'éthanol de $0,44 \mathrm{~g} / \mathrm{g}$ (97\% du rendement théorique) et une productivité volumique de $0,57 \mathrm{~g} / \mathrm{l} \cdot \mathrm{h}$, ce qui constitue des résultats encourageants. Par une approche analogue, une souche recombinante capable de fermenter efficacement l'arabinose a été également construite [164].

Sa tolérance vis-à-vis de l'éthanol et des inhibiteurs, ses performances élevées sur glucose, sa capacité à croître sur des concentrations élevées en sucres font de Z. mobilis recombiné l'un des micro-organismes les plus prometteurs pour la fermentation alcoolique des pentoses.

Cependant, il subsiste les inconvénients liés à l'instabilité des souches recombinées, à un $\mathrm{pH}$ de fermentation relativement élevé augmentant les risques de contamination, et à une plus grande complexité de mise en œuvre industrielle.

D'autres bactéries mésophiles présentent l'avantage de pouvoir fermenter naturellement les pentoses en l'absence d'oxygène et d'avoir des taux de croissance supérieurs aux levures. Dans ce groupe, les plus étudiées ont été les entérobactéries Escherichia coli et Klebsiella. Là encore, les outils génétiques ont été utilisés afin d'accroître leurs performances.

En conditions anaérobies, E. coli produit surtout des acides organiques et les rendements d'éthanol sont faibles. Des travaux d'amélioration génétique d'E. coli ont été menés dans plusieurs laboratoires [165-167]. Des gènes provenant de Z. mobilis et codant pour la PDC (pyruvate décarboxylase) et l'ADH (alcool déshydrogénase), ont été transférés chez la souche E. coli 11303 par l'intermédiaire du plasmide pLo 1297. Des rendements proches du rendement maximum ont été obtenus avec ces souches recombinées [166-169] (tableau 7). Cependant, la plupart de ces résultats ont été obtenus sur des milieux synthétiques enrichis en facteurs de croissance. D'après Hahn Hägerdal et al. [170], la production $\mathrm{d}$ 'acides organiques reste cependant non négligeable avec ces souches recombinées.

Le problème majeur concerne toujours la stabilité génétique de ces souches recombinées pour lesquelles il faut maintenir une pression de sélection sous antibiotique afin d'assurer la stabilité des plasmides, ce qui complique considérablement la mise en œuvre de tels micro-organismes. Afin d'améliorer leur stabilité génétique, les souches ont progressivement été transformées en intégrant directement sur le chromosome l'opéron portant les gènes de la PDC et de l'ADH. Il s'agit de la souche E. coli KO11 développée par l'équipe d'Ohta et al. [171]. Cependant, une pression de sélection est toujours nécessaire pour garantir sa stabilité génétique. Pour s'affranchir de ce problème, Hespell et al. [172] ont développé une souche recombinée à partir d'un mutant (souche FMJ39) incapable de croître en anaérobiose. D'après ces auteurs, de fortes productivités sont obtenues par cette souche, sans qu'aucun résultat chiffré ne soit cité.

D'autres inconvénients ont également été rapportés avec l'utilisation de E. coli. La fermentation se fait à $\mathrm{pH}$ élevé, accentuant ainsi les risques de contamination. Mais surtout, le milieu de fermentation doit être préalablement enrichi en nutriments (facteurs de croissance, vitamines) et les performances 
TABLEAU 7

Performances de E. coli recombiné sur xylose

Xylose fermentation performance by recombinant E. coli strains

\begin{tabular}{l|c|c|c|c|c|c}
\hline & Types de milieu & Xylose $(\mathrm{g} / \mathrm{l})$ & Rendement $^{\mathrm{a}}(\mathrm{g} / \mathrm{g})$ & Prod. $^{\mathrm{b}}(\mathrm{g} / \mathrm{l} \cdot \mathrm{h})$ & Éthanol $^{\mathrm{c}}(\mathrm{g} / \mathrm{l})$ & Références $^{-}$ \\
\hline E. coli (ATCC11303 pL01297) & Complexe & 80 & 0,48 & 0,7 & 39,2 & {$[167]$} \\
E. coli (ATCC11303 pL01297) & Complexe & 80 & 0,52 & 0,6 & 42 & {$[166]$} \\
E. coli (ATCC11303 pL01297) & Complexe & 80 & 0,47 & 1 & 36 & {$[171]$} \\
E. coli (ATCC11303 KO11) (frd, pdc, adhB) & Complexe & 80 & 0,53 & 1,3 & 41,6 & {$[171]$} \\
E. coli (ATCC11303 pL01297) & Complexe & 80 & 0,45 & 0,47 & 36 & {$[168]$} \\
E. coli (ATCC11303 pL01297) & Défini & 64,5 & 0,43 & 0,29 & 28 & {$[168]$} \\
E. coli (ATCC11303 pL01297) & Complexe & 140 & 0,45 & 0,46 & 56 & {$[174]$} \\
\hline
\end{tabular}

a : rendement basé sur le xylose consommé

$\mathrm{b}$ : productivité maximale

c : concentration maximale

TABLEAU 8

Performances de Kl. oxytoca et Kl. planticola recombinés sur xylose

Xylose fermentation performance by recombinant Kl. oxyotoca and Kl. planticola strains

\begin{tabular}{l|c|c|c|c|c|c}
\hline & Milieu & Xylose $(\mathrm{g} / \mathrm{l})$ & Rendement $^{\mathrm{a}}(\mathrm{g} / \mathrm{g})$ & Productivite $^{\mathrm{b}}(\mathrm{g} / \mathrm{l} . \mathrm{h})$ & Éthanol $^{\mathrm{c}}(\mathrm{g} / \mathrm{l})$ & Références $^{-}$ \\
\hline Kl. oxytoca $(\mathrm{pdc}, \mathrm{adhB})$ & complexe & 100 & 0,48 & 2 & 46 & {$[175]$} \\
Kl. planticola $(\mathrm{pdc})$ & complexe & 67 & - & 1,6 & 24 & {$[176]$} \\
Kl. planticola $(\mathrm{pdc})$ & complexe & 80 & 0,40 & 0,44 & 32 & {$[176]$} \\
Kl. planticola $\left(\mathrm{pdc}, \mathrm{pfl}^{-}\right)$ & complexe & 41 & 0,237 & 0,3 & 17,8 & {$[177]$} \\
\hline
\end{tabular}

a : rendement basé sur le xylose consommé

$\mathrm{b}$ : productivité maximale

$\mathrm{c}$ : concentration maximale

fermentaires sur hydrolysats se révèlent médiocres, en raison de la sensibilité à l'éthanol et aux inhibiteurs [173].

Des souches recombinées de Klebsiella oxytoca portant les gènes de Z. mobilis codant pour la PDC et l'ADH ont permis d'atteindre des productivités maximales doubles de celles d'E. coli [175], (tableau 8). Tolann et Finn [176] ont étudié la fermentation du xylose par une souche génétiquement recombinée de Klebsiella planticola par insertion du gène codant pour la PDC de Z. mobilis. Ils ont obtenu des performances intéressantes. Cette souche présente l'intérêt supplémentaire de ne pas nécessiter de pression de sélection pour conserver le plasmide, et de bénéficier d'une tolérance convenable à l'éthanol. Cependant, il se pose le problème de perception négative de Klebsiella, car il existe de nombreuses souches pathogènes chez ce genre bactérien.

\subsubsection{Performances sur hydrolysats}

La majorité des performances décrites précédemment ont été obtenues sur des milieux synthétiques. Comparés à ceux-ci, les hydrolysats sont des milieux de fermentation relativement hostiles aux micro-organismes, à cause de la présence de nombreux composés inhibiteurs, généralement produits lors de la phase de prétraitement (acide acétique, furfural, phénols, acides aromatiques, aldéhydes, sulfites, lignosulfates, certains ions, etc.) [62].

On peut identifier deux stratégies pour faire face à ces problèmes d'inhibitions :

- Détoxification des hydrolysats avec des résines échangeuses d'ions [178, 179], par entraînement à la vapeur [180] ou rétroévaporation. Ces procédés de détoxification conduisent à des surcoûts supplémentaires importants, incompatibles avec l'économie globale du procédé.

- Sélection de micro-organismes adaptés aux inhibiteurs présents.

Les performances obtenues sont à relier aux types de prétraitement et d'hydrolyse réalisés, ainsi qu'à la nature du substrat utilisé. Elles sont généralement nettement plus faibles comparativement à celles déterminées sur milieux synthétiques (tableaux 9 et 10). Les souches testées sur hydrolysats sont 
TABLEAU 9

Performances de E. coli recombiné sur hydrolysats

Xylose fermentation performance by recombinant E. coli strains on lignocellulosic hydrolysates

\begin{tabular}{|c|c|c|c|c|c|c|c|}
\hline & Hydrolysat & Traitement & Sucres $(g / l)$ & Rendement $^{\mathrm{a}}(\mathrm{g} / \mathrm{g})$ & Prod. $^{b}(g / l \cdot h)$ & Éthanol $^{\mathrm{c}}(\mathrm{g} / \mathrm{l})$ & Références \\
\hline E.coli (ATCC11303 pL01297) & $\begin{array}{c}\text { Peuplier** } \\
\text { non détoxifié }\end{array}$ & $\begin{array}{c}\text { Imprégnation } \mathrm{SO}_{2} \\
\text { extrudeur }\end{array}$ & $36 \mathrm{xyl}^{(1)}$ & 0,46 & 0,29 & 16,6 & {$[173]$} \\
\hline E.coli $(\mathrm{K} 011)$ & Pin* détoxifié & $\begin{array}{c}\text { Imprégnation } \mathrm{SO}_{2} \\
\left(160^{\circ} \mathrm{C}\right)\end{array}$ & $\begin{array}{c}20 \mathrm{xyl} \\
15 \mathrm{glc}^{(2)}\end{array}$ & 0,42 & 1,53 & 31 & {$[183]$} \\
\hline E.coli (ATCC11303 pL01297) & $\begin{array}{l}\text { Peuplier* } \\
\text { détoxifié }\end{array}$ & $\begin{array}{c}\text { Imprégnation } \mathrm{SO}_{2} \\
\text { extrudeur }\end{array}$ & $80 \mathrm{xyl}$ & 0,45 & 0,46 & 17,2 & {$[169]$} \\
\hline E.coli (ATCC11303 pL01297) & $\begin{array}{l}\text { Peuplier* } \\
\text { détoxifié }\end{array}$ & $\begin{array}{c}\text { Imprégnation } \mathrm{SO}_{2} \\
\text { extrudeur }\end{array}$ & $64,5 \mathrm{xyl}$ & 0,45 & 0,62 & 29,6 & [26] \\
\hline \multicolumn{4}{|c|}{$\begin{array}{l}\mathrm{a}: \text { rendement basé sur les sucres totaux consommés (pentoses et hexoses) } \\
\mathrm{b}: \text { productivité maximale } \\
\mathrm{c}: \text { concentration maximale }\end{array}$} & $\begin{array}{l}\text { (1) xylose } \\
\text { (2) glucose }\end{array}$ & \multicolumn{3}{|c|}{$\begin{array}{l}* \text { hydrolysat total } \\
* * \text { hydrolysat d'hémicelluloses }\end{array}$} \\
\hline
\end{tabular}

TABLEAU 10

Performances des levures sur hydrolysats lignocellulosiques

Xylose fermentation performance by xylose fermenting yeast on lignocellulosic hydrolysate

\begin{tabular}{|c|c|c|c|c|c|c|c|}
\hline & Hydrolysat & Traitement & Sucres $(g / l)$ & Rendement $^{\mathrm{a}}(\mathrm{g} / \mathrm{g})$ & Prod. $^{c}(\mathrm{~g} / \mathrm{l} \cdot \mathrm{h})$ & Éthanol (g/l) & Références \\
\hline C. shehatae (ATCC22984) & $\begin{array}{l}\text { Orge entière } \\
\text { hydrol. total }^{*}\end{array}$ & $\begin{array}{c}\text { Hydrolyse } \\
\text { enzymatique }\end{array}$ & $\begin{array}{l}54 \mathrm{xyl} \\
126 \mathrm{glc}\end{array}$ & $0,48^{\mathrm{a}}$ & 1,16 & 84 & {$[128]$} \\
\hline C. shehatae (CSIR-22984) & $\begin{array}{l}\text { Chêne rouge } \\
\text { hydrol. HC } \text { HC }^{* *}\end{array}$ & Hydrolyse acide & $\begin{array}{l}40 \mathrm{xyl} \\
3 \mathrm{glc}\end{array}$ & $0,25^{\mathrm{b}}$ & 0,05 & 10 & {$[186]$} \\
\hline P. stipitis (CBS 5776) & $\begin{array}{c}\text { Peuplier } \\
\text { hydrol. HC }\end{array}$ & $\begin{array}{c}\text { Hydrol. enzymat. } \\
\text { détoxifié }\end{array}$ & $\begin{array}{l}20,5 \mathrm{xyl} \\
2,7 \mathrm{glc}\end{array}$ & $0,47^{\mathrm{a}}$ & 0,2 & 11 & [187] \\
\hline P. stipitis (CBS 5776) & $\begin{array}{c}\text { Peuplier } \\
\text { hydrol. HC }\end{array}$ & $\begin{array}{l}\text { Hydrol. acide } \\
\text { détoxifié }\end{array}$ & $\begin{array}{c}19,3 \mathrm{xyl} \\
1,6 \mathrm{glc}\end{array}$ & $0,41^{\mathrm{a}}$ & 0,13 & 85 & {$[187]$} \\
\hline P. stipitis (NRRL-Y7124) & $\begin{array}{l}\text { Eucalyptus } \\
\text { hydrol. HC }\end{array}$ & $\begin{array}{c}\text { Acide dilué } 0,5 \% \\
120^{\circ} \mathrm{C}, 3 \mathrm{~h}\end{array}$ & $\begin{array}{c}30,5 \mathrm{xyl} \\
1,5 \mathrm{glc}\end{array}$ & $0,35^{\mathrm{a}}$ & 0,16 & - & {$[188]$} \\
\hline P. stipitis (CBS 5776) & $\begin{array}{c}\text { Bagasse } \\
\text { hydrol. HC }\end{array}$ & Non détoxifié & $\begin{array}{l}40,9 \mathrm{xyl} \\
3,1 \mathrm{glc}\end{array}$ & $0,27^{\mathrm{a}}$ & 0,15 & - & {$[189]$} \\
\hline P. stiitis (CBS 5776) & $\begin{array}{c}\text { Bagasse } \\
\text { hydrol. HC }\end{array}$ & Détoxifié & $\begin{array}{c}40,9 \mathrm{xyl} \\
3,1 \mathrm{glc}\end{array}$ & $0,37^{\mathrm{a}}$ & 0,56 & - & {$[189]$} \\
\hline P. stipitis (CBS 5773) & $\begin{array}{c}\text { Bagasse } \\
\text { hydrol. total }\end{array}$ & $\begin{array}{c}\text { Prétr. alcalin } \\
\text { hydrolyse acide }\end{array}$ & 140 au total & $0,35^{\mathrm{a}}$ & 0,34 & 24 & {$[190]$} \\
\hline P. stipitis & $\begin{array}{c}\text { Peuplier } \\
\text { hydrol. total }\end{array}$ & $\begin{array}{l}\text { Prétr. explosion } \\
\text { vapeur }+\mathrm{SO}_{2} \\
\text { hydrol. enzym. }\end{array}$ & $\begin{array}{l}28 \mathrm{xyl} \\
64 \mathrm{glc}\end{array}$ & $\begin{array}{l}0,45^{\mathrm{a}} \\
0,47^{\mathrm{b}}\end{array}$ & 0,85 & 41 & {$[182]$} \\
\hline
\end{tabular}

a : rendement basé sur les sucres totaux consommés (pentoses et hexoses)

$\mathrm{b}$ : rendement basé sur les sucres totaux présents initialement (pentoses et hexoses)

c : productivité maximale
* hydrolysat total

** hydrolysat hémicellulosique 
essentiellement des levures ( $P$. stipitis ou $C$. shehatae) ou des bactéries (E. coli recombiné) dont les performances étaient déjà médiocres sur milieux synthétiques. De plus, la détoxification du milieu est presque systématiquement pratiquée [183, 184], préalablement à la fermentation.

Outre la présence d'inhibiteurs dans les hydrolysats, la présence de glucose inhibe ou retarde l'utilisation du xylose [180-182, 185]. Il faut également remarquer que l'arabinose peut constituer jusqu'à $10 \%$ des sucres totaux de certains hydrolysats et, qu'à ce jour, aucun micro-organisme capable de fermenter efficacement l'arabinose en éthanol n'a encore été identifié [123], bien que le NREL ait récemment développé des souches modifiées de Z. mobilis capables de fermenter ce sucre (164).

\subsection{Fermentation du cellobiose}

Le cellobiose est un dimère de glucose présent dans les hydrolysats et provenant de l'hydrolyse incomplète de la cellulose. La capacité à fermenter le cellobiose est retrouvée chez certaines souches de levures [191]. D'après Grohmann [191], des genres tels que Brettanomyces [192, 193], Hansenula [194], Candida [193] peuvent fermenter 100 à $200 \mathrm{~g} / \mathrm{l}$ de glucose et cellobiose en produisant 40 à $95 \mathrm{~g} / \mathrm{l}$ d'éthanol. Spindler et al. (195) ont recherché des souches, notamment parmi Brettanomyces custersii, capables de fermenter à la fois le cellobiose et le glucose avec des performances comparables à $S$. cerevisiae sur hexoses. Doran et Ingram [196] ont développé des souches génétiquement modifiées de Klebsiella oxytoca capables de fermenter le cellobiose. Après prétraitement acide de la bagasse, ils ont obtenu un rendement d'éthanol de $0,39 \mathrm{~g} / \mathrm{g}$ de sucre, et une productivité de $0,56 \mathrm{~g} / \mathrm{l} . \mathrm{h}$.

\subsection{Stratégies de fermentation des hydrolysats}

Pour les hydrolysats totaux, la présence conjointe de glucose et de pentoses peut constituer un problème d'optimisation des performances fermentaires. Deux technologies se sont développées pour tenter de remédier à ce problème : la fermentation en coculture et la fermentation séquentielle.

Concernant les hydrolysats séparés issus de la fraction cellulosique, les technologies de SFS ou DMC se sont particulièrement développées ces dernières années. Quant à la fermentation des hydrolysats séparés issus de la fraction hémicellulosique, nous avons vu précédemment qu'elle se heurtait toujours aux problèmes des faibles performances permises par les micro-organismes capables d'utiliser les pentoses.

\subsubsection{Fermentation en coculture}

Cette approche consiste à cultiver ensemble deux microorganismes qui fermentent, l'un le glucose et l'autre les pentoses, en éthanol. La notion de coculture s'adresse à un hydrolysat total, et la fermentation des pentoses et du glucose a lieu dans le même réacteur, ce qui permet de diminuer les coûts d'investissement. La plupart des travaux ont concerné des cocultures avec deux levures : $S$. cerevisiae pour fermenter le glucose, et $P$. stipitis pour fermenter le xylose.

Mais les obstacles à la mise en œuvre d'un tel procédé sont nombreux :

- La fermentation du xylose se fait toujours plus lentement que la fermentation du glucose et il se pose finalement le problème de l'inhibition par l'éthanol du micro-organisme fermentant le xylose.

- Il existe une répression catabolique exercée par le glucose sur l'utilisation du xylose. En effet, cultivés sur un mélange de sucres, les micro-organismes utilisent préférentiellement le glucose. Pour s'affranchir de ce problème, l'équipe de l'Institut national de la recherche agronomique de Narbone [197] a tenté de sélectionner une souche de P. stipitis ou C. shehatae incapable d'utiliser le glucose.

- Il y a compétition entre $S$. cerevisiae et la levure fermentant le xylose pour la consommation de l'oxygène du milieu qui joue un rôle primordial dans la fermentation alcoolique du xylose par $P$. stipitis. Pour éviter cette concurrence, Laplace et al. [197] ont développé un mutant respiratoire de Saccharomyces incapable d'utiliser l'oxygène.

- Il peut y avoir incompatibilité entre souches cocultivées. Des tests de compatibilité ont ainsi mis en évidence une activité "inhibitrice" d'une souche de $P$. stipitis à l'encontre de S. cerevisiae.

Des cocultures entre $S$. cerevisiae et $C$. shehatae [198], $S$. cerevisiae et $P$. stipitis $[199,200], S$. cerevisiae et $P$. tannophilus [201] ont été expérimentées, mais à chaque fois, le taux de conversion alcoolique du xylose restait faible. Laplace et al. [197] ont mis en place un schéma de coculture à haute densité cellulaire, en utilisant $P$. stipitis et un mutant déficient respiratoire de $S$. diastaticus. À partir d'un mélange de glucose et xylose ( $50 \mathrm{~g} / \mathrm{l}$ de sucres), le rendement global était de $0,41 \mathrm{~g} / \mathrm{g}$ et la productivité globale de $3,1 \mathrm{~g} / \mathrm{l}$.h, avec un taux de conversion des sucres de $100 \%$. Mais ces résultats ne permettent pas de différencier les performances liées à $S$. diastaticus sur glucose des performances liées à $P$. stipitis sur xylose. En outre, l'expérimentation a été conduite sur un milieu synthétique enrichi en nutriments. La fermentation d'un hydrolysat total de bois de peuplier par cette même coculture conduit à un faible rendement $(0,25 \mathrm{~g} / \mathrm{g})$ et une productivité de 0,93 g/l.h [197].

Laplace et al. [202] ont par la suite développé la coculture à haute densité cellulaire, en utilisant la technique de recyclage par microfiltration. En associant un mutant respiratoire de $S$. cerevisiae incapable d'utiliser l'oxygène avec $P$. stipitis, ils ont obtenu un rendement de $0,43 \mathrm{~g}$ d'éthanol/g de sucres présents dans le milieu, et une productivité de $2 \mathrm{~g} / \mathrm{l} \cdot \mathrm{h}$, avec un taux de conversion du substrat de $88 \%$. En utilisant un 
hydrolysat total de bois de peuplier comme source de glucose $(41 \mathrm{~g} / \mathrm{l})$ et xylose $(9 \mathrm{~g} / \mathrm{l})$, l'éthanol est produit avec un rendement de $0,45 \mathrm{~g} / \mathrm{g}$ de sucres, et une vitesse de $2,9 \mathrm{~g} / \mathrm{l} \cdot \mathrm{h}$, avec un taux de conversion du substrat de $96 \%$.

\subsubsection{Fermentation séquentielle}

Une autre approche consiste à réaliser successivement la fermentation du glucose et celle du xylose : c'est le principe de la fermentation séquentielle. Les performances obtenues en fermentation séquentielle sont généralement faibles [200, 203]. Cependant, des résultats encourageants ont été obtenus récemment par l'équipe de Lindsay et al. [204]. Ils ont développé une fermentation séquentielle à deux étages, en utilisant une souche mutante d'E. coli incapable d'utiliser le glucose dans le premier étage, et de $S$. cerevisiae dans le second étage. Un mélange de glucose (30 g/l), d'arabinose (30 g/l) et de xylose $(30 \mathrm{~g} / \mathrm{l})$ a été fermenté en $72 \mathrm{~h}$. Ces résultats semblent prometteurs, cependant, le problème d'instabilité des souches mutantes n'est pas résolu.

\subsubsection{Saccharification et fermentation simulta nées (SFS)}

Ce procédé combine en une seule étape l'hydrolyse enzymatique de la cellulose et la fermentation des sucres produits. Il ne concerne donc que la fermentation du glucose, bien qu'à l'avenir, il se pourrait que la SFS englobe à la fois la fermentation du glucose et des pentoses, si une souche capable de fermenter les deux sucres à la fois était mise au point.

Les cellulases ont une activité optimale à $50^{\circ} \mathrm{C}$, alors que la température optimale de fermentation des levures est inférieure ou égale à $35^{\circ} \mathrm{C}$ [198]. L'axe prioritaire des recherches porte donc sur la sélection des souches thermotolérantes [198, 206-211]. Certaines souches de Saccharomyces cerevisiae sont capables de croître à $37^{\circ} \mathrm{C}$, de même que certaines souches de $S c h$. pombe sont capables de croître à $41^{\circ} \mathrm{C}$ [212]. D'après Beall et al. [213], Kluyveromyces marxianus et Kluyveromyces fragilis seraient les meilleures souches pour produire de l'éthanol à température élevée. Ballesteros et al. [198] ont testé 27 souches appartenant aux genres Candida, Saccharomyces et Kluyveromyces pour leur capacité à fermenter le glucose à des températures comprises entre $32^{\circ} \mathrm{C}$ et $45^{\circ} \mathrm{C}$. Les productivités les plus élevées ont également été obtenues avec Kl. marxianus et Kl. fragilis. À $42^{\circ} \mathrm{C}$, elles ont permis une production de $38 \mathrm{~g} / \mathrm{l}$ d'éthanol en $78 \mathrm{~h}$, avec un rendement de $0,5 \mathrm{~g} / \mathrm{g}$. Il a également été proposé d'améliorer l'efficacité de la SFS à haute température, par extraction continue de l'éthanol afin que la concentration inhibitrice ne soit pas atteinte [214].

Des recherches au NREL ont montré que la SFS pouvait être une voie économique et efficace pour convertir la cellulose en éthanol [46, 215]. D'après Philippidis [216], la SFS contribuerait à réduire de $23 \%$ les coûts de production de l'éthanol à partir de la biomasse cellulosique. La SFS est également à la base d'une technologie sur le point d'être commercialisée par la compagnie Swan Biomass aux États-Unis, qui est un partenariat entre Amoco Corporation et Stone \& Webster Inc. L'université de Purdue (États-Unis) a également développé récemment un procédé SFS à l'échelle pilote, mais selon un mode continu, le procédé CSRS (Continuous Stirred Reactor Separator), qui permet d'effectuer simultanément la saccharification, la fermentation et la récupération de l'éthanol [217].

Les avantages que procurent la SFS sont nombreux. Étant donné que les sucres sont fermentés immédiatement après leur production, les risques d'inhibition par les produits terminaux d'hydrolyse sont réduits [218]. Il en résulte une augmentation des taux de conversion, une augmentation des rendements et de la concentration en éthanol, et une réduction de la concentration en enzyme nécessaire [198, 208, 219]. En outre, le coût des équipements est réduit (un seul réacteur) et la présence d'éthanol durant l'hydrolyse diminue les risques de contaminations.

Cependant, le procédé SFS doit encore être optimisé. Les études devront porter sur :

- l'influence de la concentration en substrats et en enzymes sur la productivité ;

- l'effet des prétraitements sur l'efficacité de la SFS ;

- le développement de souches thermotolérantes, capables de meilleures performances et plus résistantes à l'éthanol.

\subsubsection{Procédé DMC (Direct Microbial Conversion)}

Le procédé DMC est une variante de la SFS, qui n'utilise qu'une seule étape (et généralement un seul microorganisme) pour réaliser la production d'enzymes, l'hydrolyse de la cellulose et la fermentation alcoolique des sucres.

Clostridium thermocellum est l'un des micro-organismes pouvant présenter le plus d'intérêt pour ce procédé [220]. D'après Ahn et Lynd [221], Cl. thermocellum est capable de rendements d'éthanol élevés car il formerait moins de coproduits par rapport aux autres bactéries thermophiles. Il peut produire de l'éthanol même en concentration élevée en substrat et il serait particulièrement bien adapté aux applications à grande échelle. Par contre, $\mathrm{Cl}$. thermocellum est incapable de fermenter les pentoses. De plus, la croissance de $\mathrm{Cl}$. thermocellum n'a été possible qu'à un $\mathrm{pH}>6$, et dans un milieu enrichi en facteurs de croissance et en vitamines. Ahn et Lynd [221] ont essayé de développer de nouvelles souches de $\mathrm{Cl}$. thermocellum pouvant croître à $\mathrm{pH}$ faible, et ne nécessitant pas l'ajout de vitamines et facteurs de croissance. Mais les résultats obtenus jusqu'à présent ne sont pas prometteurs en terme de rendement éthanolique. Une coculture entre $C l$. thermocellum et $C l$. saccharolyticum a également été étudiée, mais les rendements sont faibles en raison de la production importante d'acides organiques [222]. 


\subsection{Conclusion}

Les performances des levures fermentant naturellement les pentoses n'ont pas significativement progressé, malgré les nombreux travaux effectués. En outre, la nécessité de contrôler le niveau d'oxygène et la sensibilité à l'éthanol sont deux inconvénients difficilement surmontables. Pour leur part, les bactéries thermophiles sont difficilement envisageables en raison de leurs performances médiocres, ainsi que de la complexité de mise en œuvre industrielle. Quant aux entérobactéries recombinées (E. coli et Klebsiella), elles sont trop exigeantes en facteurs de croissance et en vitamines et trop sensibles aux inhibiteurs présents dans les hydrolysats. De plus, on ne connaît pas leur comportement en conditions industrielles, et se posera toujours la question de l'instabilité des souches recombinées. Les deux voies qui semblent les plus prometteuses aujourd'hui concernent l'amélioration génétique des souches de $S$. cerevisiae et de Z. mobilis, qui sont naturellement capables de fermenter très efficacement le glucose en éthanol. Le développement des outils génétiques devrait leur permettre de pouvoir assimiler et transformer efficacement les pentoses en éthanol. Il semble en effet préférable d'adapter aux pentoses des micro-organismes qui savent déjà produire de l'alcool.

Quant à la technologie à privilégier, il semble à l'heure actuelle que la SFS soit la voie la plus prometteuse, particulièrement du point de vue économique (économies sur la consommation d'enzymes, sur les volumes de réacteurs, etc.). La recherche de souches thermotolérantes doit se poursuivre parmi les souches de $S$. cerevisiae et éventuellement Z. mobilis. Ces souches sont d'autant plus intéressantes qu'elles pourraient à la fois fermenter les pentoses et le glucose, ce qui permettrait de réaliser la fermentation des sucres totaux dans le même réacteur avec un seul micro-organisme.

\section{DISCUSSION}

Les procédés d'hydrolyse chimique, bien qu'étant les seuls à avoir connu dans le passé un développement jusqu'au stade industriel, sont aujourd'hui quasiment abandonnés. Le coût élevé des acides et des techniques de recyclage, les problèmes technologiques de corrosion des matériels, les faibles rendements de récupération des sucres et la production importante de déchets de neutralisation ont condamné ces procédés.

L'hydrolyse enzymatique est une technique beaucoup plus récente, dont les perspectives de développement paraissent plus prometteuses. Elle permet de meilleurs rendements de récupération des sucres, tout en étant moins contraignante sur le plan technologique. La limite actuelle de l'hydrolyse enzymatique est liée à son coût. Ce n'est pas au niveau des méthodes de prétraitement que des progrès importants sont à attendre, mais plutôt au niveau de l'étape d'hydrolyse enzymatique elle même. Les axes à privilégier au niveau de la recherche devraient permettre d'améliorer l'efficacité et la qualité des enzymes, tout en essayant de réduire dans la mesure du possible le coût de production de ces enzymes. Le développement du procédé SFS, avec la recherche de souches de levures à la fois thermotolérantes et performantes sur glucose, devrait également permettre d'améliorer la rentabilité économique de l'hydrolyse enzymatique.

Bien qu'ayant fait l'objet de nombreux travaux de recherche ces quinze dernières années, le problème de la fermentation des pentoses n'est toujours pas résolu. Le développement des outils génétiques, et les nouvelles voies de recherches avec $S$. cerevisiae et $Z$. mobilis devraient permettre d'améliorer les performances de la fermentation alcoolique sur pentoses. Les efforts de recherches devraient éventuellement permettre d'aboutir à terme à la sélection d'un micro-organisme capable de fermenter efficacement à la fois les pentoses et le glucose, ce qui simplifierait le procédé et permettrait des économies substantielles.

Cette analyse bibliographique a également permis de mettre en évidence l'hétérogénéité des expérimentations entre les différentes équipes. Il est par exemple difficile de faire une comparaison entre les différentes cinétiques d'hydrolyse enzymatique mesurées, car les substrats, les quantités d'enzymes et le type d'enzymes sont très variables d'une équipe à l'autre. Ce manque de standardisation se répercute forcément sur la façon d'évaluer l'efficacité des prétraitements, sachant que celle-ci est évaluée par le taux d'hydrolyse enzymatique. De même, l'échelle d'expérimentation n'est jamais la même (laboratoire ou pilote).

Une autre limite de l'analyse bibliographique est liée aux imprécisions, tant au niveau de la description du procédé qu'au niveau des résultats rapportés. Par exemple, le mode de préparation du substrat n'est pas systématiquement explicité, de même que la granulométrie initiale du substrat n'est pas toujours précisée. Or, les dépenses énergétiques de broyage ne seront pas les mêmes pour un substrat de quelques centimètres de granulométrie ou quelques millimètres. Cette imprécision se retrouve au niveau de l'expression des rendements. Il n'est pas toujours précisé si le rendement d'éthanol est exprimé par rapport à la matière sèche initiale ou bien par rapport à la matière sèche hydrolysée, alors que les pertes en matières sèches au cours du procédé peuvent parfois atteindre plus de $30 \%$. De même, la composition réelle des substrats en leurs trois fractions principales ne peut être connue avec précision, en raison des difficultés analytiques de ce type de mesure. L'estimation de l'activité réelle de l'enzyme est également difficile à évaluer, car la méthode actuelle de mesure de cette activité sur papier filtre est généralement peu reproductible d'un laboratoire à un autre.

Il serait également préférable à l'avenir que les équipes intègrent d'avantage le procédé dans son ensemble, et qu'elles ne s'intéressent pas seulement à une ou deux étapes, puisque toutes les étapes sont plus ou moins interdépendantes. 
L'exemple caractéristique est celui de la spécialisation des équipes, soit pour l'hydrolyse, soit pour la fermentation. Or, les conditions expérimentales du prétraitement ou de l'hydrolyse influencent les performances des micro-organismes (les composés de dégradation qui seront produits lors du prétraitement pourront inhiber l'activité de certains microorganismes).

Un effort de standardisation doit donc avoir lieu, au moins pour les tests d'évaluation de l'efficacité des prétraitements, et pour les tests relatifs à la fermentation des hydrolysats. Quant aux voies de recherche à privilégier, elles devront permettre :

- d'améliorer l'efficacité des techniques de prétraitement, dans les conditions les moins sévères possibles ;

- d'améliorer l'efficacité des enzymes et de les produire de façon plus économique ;

- d'améliorer les rendements de récupération des sucres, et les taux de conversion en éthanol, à la fois pour les pentoses et le glucose.

\section{REMERCIEMEN TS}

Cette étude a été réalisée dans le cadre d'un groupe de travail mis en place par le groupement d'intérêt scientifique Agrice (Agriculture pour la chimie et l'énergie), chargé d'élaborer un programme de recherche sur la valorisation non alimentaire des substrats végétaux.

Cette étude a été financée conjointement par l'Ademe (Agence de l'environnement et de la maîtrise de l'énergie) et l'ITCF (Institut technique des céréales et des fourrages).

\section{RÉFÉREN CES}

1 Gong, C.S,. Maun C.M.,et Tsao, G.T. (1981) Direct Fermentations of Cellulose to Ethanol by a Cellulolytic Filamentous Fungus Monilia sp. Biotech. Lett., 3, 2, 131-144.

2 Grethlein, H.E. (1985), Acid Hydrolysis review. In Anaerobic digestion and carbohydrate hydrolysis of Waste, Ferraro, G.L., Ferranti, M.P., et Naveau, H., eds., Elsevier, Londres, 14

3 Parisi, F. (1989) Advances in Lignocellulosics Hydrolysis and the Utilization of the Hydrolysates. Advances in Biochemical Engineering/Biotechnology, 53-87.

4 Brennen, A.H., Hoagland, W. et Schell, D.J. (1987). High Temperature Acid Hydrolysis of Biomass Using an Engineering-Scale Plug Flow Reactor: Results of Lows Solids Testing. Biotechn. Bioeng. Symp., 17, 53-70.

5 Kwarteng, I.K. (1983) Kinetics of Acid Hydrolysis of Hardwood in a Continuous Plug Flow Reactor. Thèse, Darthmouth College, Hanove, NH.

6 Brenner, W., Rugg, B., Arnon, J., Cleland, M. et Rogers, C. (1979) Radiation Pretreatments for Optimizing the Sugar Yield in the Acid Hydrolysis of Waste Cellulose. Radiat. Phys. Chem., 14, 299-308.

7 Teng, K.F., Mutharasan, R. et Grossmann, E.D. (1983) Papier. AIChE Annual Meeting, 30 oct.-3 nov., Washington, DC.

8 Jones, J.L. et Semrau, K.T. (1984) Wood Hydrolysis for Ethanol Production-Previous Experience and the Economics of Selected Processe. Biomass, 5, 109-135.
9 Wright, J.D. et d'Agincourt, C.G. (1984), Evaluation of Sulfuric Acid Hydrolysis Processes for Alcohol Fuel Production. SERI/TR-231-2074, Solar Energy Research Institute, Golden CO.

10 Wright, J.D., Bergeron, P.W. et Wendene, P.J. (1985) The Processing Batch Hydrolysis Reactor. SERI/TP-232-2803, Solar Energy Research Institute, Golden CO.

11 Bergeron, P.W., Wright, J.D et Werdene, P.J. (1986) Progressing-Batch Hydrolysis Reactor Single Stage Experiments. Biotechnol. Bioeng. Symp., 17, 33-51.

12 Elander, R., Ibsen, K., Hayward, T., Nagle, N. et Torget, R. (1997) Overall Process Considerations for Using Dilute Acid Cellulose Hydrolysis Technology to Produce Ethanol from Biomass. In Making a Business from Biomass in Energy, Environment, Chemicals Fibers, and Materials-Proceedings of the Third Biomass Conference of the Americas, édite par Overend, R.P. et Chornet, E., 2, 1025-1034.

13 Jacquinot, B., Raymond, B. et Frontère, L. (1989) Procédé Bertin d'hydrolyse acide des matériaux lignocellulosiques. Biomass for Energy and Industry - 5th EEC Conference, Grassi, G., Gosse, G. et dos Santos, G., éds., Elsevier.

14 Brenner, W. et Rugg, B. (1985) High Temperature Dilute Acid Hydrolysis of Waste Cellulose: Batch and Continuous Processes. Rapport final PB86-143484, Université de NewYork. Environmental Protection Agency, Cincinnati, Ohio,

15 Shah, R.B., Clausen, E.C., et Gaddy, J.L. (1984) Production of Chemical Feedstocks from Biomass. CEP Newlt., January, 76.

16 Downey, K. et al. (1983) HF Hydrolysis of Wood for Ethanol Production. Industrial Energy Forum 83, 19 septembre, Nashville TN.

17 Selke, S.M., Hawley, M. et Lamport, D.T.A. (1983) Reaction Rates for Liquid-Phase HF Saccharification of Wood. In Conference Proceedings on Wood and Agricultural Residues, 329-349.

18 Ackerson, M., Ziobro, M. et Gaddy, G.L. (1981) Two-Stage Acid Hydrolysis of Biomass. Biotechnol. Bioeng. Symp. 11, 103-112.

19 Schell, D.J., Torget, R., Power, A., Walter, P.J., Grohmann, K. et Hinmann, N.D. (1991) A technical and Economic Analysis of Acid-Catalysed Steam Explosion and Dilute Sulfuric Acid Pretreatment Using Wheat Straw or Aspen Wood Chips. Appl. Biochem. and Biotechnol., 28/29, 87-97.

20 Saddler, J.N., Ramos, L.P. et Breuil, C. (1993) Steam Pretreatment of Lignocellulosic Residues. In Bioconversion of Forest and Agricultural Plant Residues, Saddler, J.N., éd., Wallingford, R.U., 73-91.

21 Sutcliffe, R., Breuil, C., Brownell, H.H. et Saddler, J.N. (1988) The Influence of Lignin Extraction Solvents on the Enzymatic Hydrolysis of Steam-Treated Aspenwood. PosterIEA Workshop on the Bioconversion of Lignocellulosics, 1216 juin, Ottawa.

22 Ramos, L.P., Breuil, C., Lushner, D.J. et Saddler, J.N. (1992) Steam Pretreatment Conditions for Effective Enzymatic Hydrolysis and Recovery Yields of Eucalyptus viminalis Wood Chips, Holzforschung, 46, 149-154.

23 Schwald, W., Smaridge, M., Chan, M. et Saddler, J.N. (1989) The Influence of $\mathrm{SO}_{2}$ Impregnation and Fractionation Product Recovery and Enzymatic hydrolysis of SteamTreated Sprucewood. In Enzyme Systems for Lignocellulose Degradation, M.P. Coughlan, éd., New York, Elsevier, 231242.

24 Datta, R. (1981) Energy Requirements for Lignocellulose Pretreatment Processes. Proc. Biochem., juin-juillet, 16-19.

25 Fan, L.T., Lee, Y. et Gharpuray, M.M. (1982) The Nature of Lignocellulosics and their Pretreatments for Enzymatic Hydrolysis. Adv. in Biochem. Eng., 23, 157-187. 
26 McMillan, J.D. (1994) Pretreating Lignocellulosics Biomass: a Review. In Enzymatic Conversion for Fuels Production, M.E. Himmel, J.O. Baker, and R.P. Overend, eds., ACS Symposium Series 566, chap. 15, American Chemical Society, 411-437

27 Chang, M.M., Chou, T.Y.C. et Tsao, G.T. (1981) Structure Pretreatment and Hydrolysis of Cellulose. Adv. in Biochem. Eng., 20, 15-42.

28 Pourquié, J. et Vandecasteele, J.P. (1993) Conversion de la biomasse lignocellulosique par hydrolyse enzymatique et fermentation. Biotechnologie, $4^{\mathrm{e}}$ édition, René Scriban, coordinateur Lavoisier TEC \& DOC, Paris, 677-700.

29 Puls, J., Poutanen, K., Korner, H.U. et Viikari, L. (1985) Biotechnical Utilization of Wood Carbohydrates after Steaming Pretreatment. Applied Microb. Biotech., 32, 416-423.

30 Miller, D., Sutcliffe, R. et Saddler, J.N. (1989) InTAPPI Proceedings of the International Symposium on Wood and Pulping Chemistry, Technical Association of the Pulp and Paper Industry, Atlanta, GA, 9-11.

31 Brownell, H.H. et Saddler, J.N. (1984) Steam Explosion Pretreatment for Enzymatic Hydrolysis. Biotechnol. Bioeng. Symp., 14, 55-68.

32 Brownell, H.H., Yu, E.K.C. et Saddler, J.N. (1986) Steam Explosion Pretreatment of Wood: Effect on Chip Size, Acid, Moisture Content and Pressure Drop. Biotechnol. Bioeng. Symp., 28, 792-801.

33 Clark, T.A., Mackie, K.L., Dare, P.H. et McDonald, A.G. (1989) Steam Explosion of the Softwood Pinus radiata with Sulphur Dioxide Addition. J. Wood Chem. Tech., 9, 2, 135-166.

34 Pourquié, J. et Vandecasteele, J.P. (1990) Biomass for Energy and Industry. 5th EC Conference, Elsevier Applied Science, Londres, 2, 52-58.

35 Ropars, M., Marchal, R., Pourquié, J., et Vandecasteele, J.P. (1992) Large Scale Enzymatic Hydrolysis of Agricultural Lignocellulosic Biomass, Partie 1: Pretreatment Procedures. Bioresource Technology, 125-130.

36 Nativel, F., Pourquié, J., Ballerini, D., Vandecasteele, J.P. et Renault, P.H. (1992) The Biotechnology Facilities at Soustons for Biomass Conversion. International Journal of Solar Energy, 11, 219-229.

37 Ballerini, D., Desmarquest, J.P., Pourquié, J., Nativel, F. et Rebeller, M. (1994) Ethanol Production from Lignocellulosics: Large Scale Experimentation and Economics. Bioresource Technology, 50, 17-23.

38 Ballerini, D., Nativel, F., Rebeller, M., Renault, P.H. et Vandecasteele, J.P. (1992) Conversion des Lignocelluloses: l'Exemple de Soustons, Biofutur, juin, 47-50.

39 Viggiano, D., Cardinale, G., Felici, F., Nanna, F. et Zimbardi, F. (1995) Steam Explosion Treatment of Poplar Wood at The Pilot Plant Level. In Biomass Energy Environ. Agric. Ind. Proc. Europ. Biomass Conf., 8th Conference, Elsevier, Oxford, United Kingdom, 1385-1392.

40 Eklund, R., Galbe, M. et Zacchi, G. (1990) Optimization of Temperature and Enzyme Concentration in the Enzymatic Saccharification of Steam Pretreated Willow. Enz. Microb. Technol., 12, 225-228.

41 Mamers, H. et Menz, D.N.J. (1984) Explosion Pretreatment of Pinus radiata Woodchips for the Production of Fermentation Substrates. Appita, 37, 8, 644-649.

42 Excoffier, G., Toussaint, B. et Vignon, M.R. (1991) Saccharification of Steam-Exploded Poplar Wood. Biotech. Bioeng., 38, 1308-1317.

43 Heitz, M., Capek-Menard, E., Koeberle, P.G., Gangne, J.et Chornet, E. (1991) Fractionation of Populus tremuloides at the Pilot Plant Scale: Optimization of Steam Pretreatment
Conditions Using the Stake II Technology. Biores. Technol., 35, 23-32.

44 Jollez, P., Chornet, E. et Overend, R.P. (1994) SteamAqueous Fractionation of Sugar Cane Bagasse: An Optimization Study of Process Conditions at the Pilot Plant Level. Adv. Thermoch. Biomass Conv., 2, 1659-1669.

45 Montane, D., Salvado, J., Farriol, X. et Chornet, E. (1993) The Fractionation of Sugar Almond Shells by ThermoMechanical Aqueous-Phase Pretreatment. Biomass and Bioenergy, 4, 6, 427-437.

46 Wright, J.D. (1988) Ethanol from Biomass by Enzymatic Hydrolysis. Chem. Eng. Prog., 84, 8, 62-74.

47 Van Walsum, G.P., Allen, S.G., Spencer, M.J., Laser, M.S., Antal, M.J. et Lynd, L.R. (1996) Conversion of Lignocellulosics Pretreated with Liquid Hot Water to Ethanol. Appl. Biochem. and Biotechnol., 57/58, 157-170.

48 Bouchard, J., Nguyen, T.S., Chornet, E. et Overend, R.P. (1990) Analytical Methodology for Biomass Pretreatment. Partie 1: Solid Residues. Biomass, 23, 243-261.

49 Bouchard, J., Nguyen, T.S., Chornet, E. et Overend, R.P. (1991) Analytical Methodology for Biomass Pretreatment. Partie 2: Characterization of the Filtrates and Cumulative Product Distribution as a Function of Treatment. Appl. Biochem. and Biotechnol., 28/29, 87-97.

50 Walch, E.A., Zemann, A., Schinner, F., Bonn, G. et Bobleter, O. (1992) Enzymatic Saccharification of Hemicellulose Obtained from Hydrothermally Pretreated Sugar Cane Bagasse and Beech Bark. Biores. Technol., 39, 173-177.

51 Mok, W.S. et Antal, M.J. (1992) Uncatalysed Solvolysis of Whole Biomass Hemicellulose by Hot Compressed Liquid Water. Ind. Eng. Chem. Res., 31, 4, 1157-1161.

52 Kohlmann, K., Westgate, P.J., Weil, J. and Ladisch, M.R. (1993) Biological-Based Systems for Waste Processing. Papier SAE \#932251, Society of Automotive Engineers, Inc., Warrendale, PA.

53 Weil, J., Westgate, P.J., Kohlmann, K., et Ladisch, M.R. (1994) Cellulose Pretreatments of Lignocellulosic Substrates. Enz. Microb. Technol., 16, 1002-1004.

54 Bobleter, O., Vidotti, R., Zemann, A. and Prutsch, W. (1989) Hydrothermal Pretreatment of Bagasse and Wheat Straw. In Biomass for Energy and Industry - 5th EC Conf., G. Grassi, G. Gross ET G. dos Santos, éds., New York, Elsevier, 2, 31-37.

55 Rivers, D.B. et Emert, G.H. (1988) Factors Affecting the Enzymatic Hydrolysis of Municipal-Solid-Waste Components. Biotech. Bioeng, 31, 278-281.

56 Gould, J.M. (1985) Studies on the Mecanism of Alkaline Peroxyde Delignification of Agricultural Residues. Biotech. Bioeng., 27, 225-231.

57 Carr, M.E. et Doane, W.M. (1984) Modification of Wheat Straw in a High-Shear Mixer. Biotech. Bioeng., 26, 12521257.

58 Gould, J.M. et Jasberg, B.K. (1991) Combined Physical and Chemical Treatment to Improve Lignocellulose Digestibility. Brevet américain, 4, 997, 488.

59 Tyson, G.J. (1991) Delignification of Non-Woody Biomass. Brevet américain, 4, 997, 488.

60 Puri, V.P. et Pearce, G.R. (1986) Alkali-Explosion Pretreated of Straw and Bagasse for Enzymatic Hydrolysis. Biotechnol. Bioeng., 28, 480-485.

61 Koullas, D.P., Chritakopoulos, P.F., Dekos, D., Macris, B.J. and Koukios, E.G. (1992), Correlating the Effect of Pretreatment on the Enzymatic Hydrolysis of Straw. Biotech. Bioeng., 39, 113-116. 
62 Hahn-Hägerdal, B., Linden, T., Senac, T. et Skoog, K. (1991), Ethanolic Fermentation of Pentoses in Lignocelluloses Hydrolysates. Appl. Biochem. and Biotechnol., 28/29, 131-144.

63 Thompson, D.N., Chen, H.C. et Grethlein, H.E. (1992), Comparison of Pretreatment Methods on the Basis of Available Surface Area. Bioresource and Technology, 39, 155-153.

64 Hayn, M., Steiner, W., Klinger, R., Steinmüller, H., Sinner, M. et Esterbauer, H. (1993) Basic Research and Pilot Studies on the Enzymatic Conversion of Lignocellulosics. In Bioconversion of Forest and Agricultural Plant Residues, Saddler, J.N., éd., Wallingford, Royaume-Uni, CAB International, 231-290.

65 Torget, R., Werdene, M., Himmel, H. and Grohmann, K. (1990) Dilute Acid Pretreatment of Short-Rotation Woody and Herbaceous Crops. Appl. Biochem. and Biotechnol., $\mathbf{2 4 / 2 5}, 115-126$.

66 Torget, R., Walter, P.J., Himmel, H. et Grohmann, K. (1991) Dilute Acid Pretreatment of Corn Residues and ShortRotation Woody Crops. Appl. Biochem. and Biotechnol., 28/29, 75-86.

67 Grohmann, K., Torget, R. et Himmel, M. (1985) Optimization of Dilute Acid Pretreatment of Biomass. Biotech. Bioeng. Symp., 15, 59-80.

68 Grohmann, K. Torget, R. et Himmel, M. (1986), Dilute Acid Pretreatment of Biomass at High Solids Concentrations. Biotech. Bioeng. Symp., 17, 135-151.

69 Grohmann, K. et Torget, R.W. (1992), Two-Stage Dilute Acid Prehydrolysis of Biomass. Brevet américain, 5, 125,977.

70 Torget, R., Himmel, H. and Grohmann, K. (1992), Dilute Acid Pretreatment of Two Short-Rotation Herbaceous Crops. Appl. Biochem. and Biotechnol., 34/35, 115-123.

71 Torget, R., Hatzis, C., Hayward, T.K., Hsu, T. et Philippidis, G.P. (1996) Optimization of Reverse-Flow, Two-Temperature, Dilute-Acid Pretreatment to Enhance Biomass Conversion to Ethanol. Appl. Biochem. and Biotechnol., 57/58, 85-101.

72 Schell, D.J., Walter, P.J. et Johnson, D.K. (1992) Dilute Sulfuric Acid Pretreatment of Corn Stover at High Solids Concentrations. Appl. Biochem. and Biotechnol., 34/35, 659-665.

73 Kadam, K.L. et Hsu, T.A. (1997) High-Solids Process for the Pretreatment of Lignocellulosic Feedstock in Bioethanol Production. In Making a Business from Biomass in Energy, Environment, Chemicals Fibers, and Materials - Proceedings of the Third Biomass Conference of the Americas, édité par Overend, R.P. et Chornet, E., 2, 1079-1090.

74 Brink, D.L. (1993) Method of Treating Biomass Material. Brevet américain, 5, 221, 357.

75 Brink, D.L. (1994), Method of Treating Biomass Material. Brevet américain, 5, 366, 558.

76 Israilides, C.J., Grant, G.A. et Han, Y.W. (1978), Sugar Level Fermentability and Acceptability of Straw Treated with Different Acids. Appl. Environ. Microbiol., 36, 1, 43-46.

77 Fan, L.T., Gharpuray, M.M. et Lee, Y. (1981) Evaluation of Pretreatment for Enzymatic Conversion of Agricultural Residues. Biotech. Bioeng. Symp., 11, 29-45.

78 Holtzapple, M.T., Cognate, M., Shu, Y. et Hendrickson, C. (1990) Inhibition of Trichoderma reesei Cellulase by Sugars and Solvents. Biotechnol. Bioeng., 36, 275-287.

79 Dale, B.E., Henk, L.L. et Shiang, M. (1985) Fermentation of Lignocellulosics Materials Treated by Ammmonia Freeze Explosion. Dev. Ind. Microbiol., 26, 223-233.

80 Dale, B. et Holtzapple, M. (1989), Technical Summary of Afex (unpublished).
81 Dale, B.E. et Moreira, M.J. (1982), A Freeze-Explosion Technique for Increasing Cellulose Hydrolysis. Biotech. Bioeng. Symp., 12, 31-43.

82 Basaglia, M., Concheri, G., Cardinali, S., Pasti-Grigsby, M.B. et Nuti, M.P. (1992) Enhanced Degradation of Ammonium-Pretreated Wheat Straw by Lignocellulosic Streptomyces spp. Can. J. Microbiol., 38, 1022-1025.

83 Ghosh, P. et Singh, A. (1993) Physiochemical and Biological Treatments for Enzymatic/Microbial Conversion of Lignocellulosic Biomass. Adv. Appl. Microbiol., 39, 295-333.

84 Eriksson, K., Grunewald, A. et Vallander, L. (1980) Studies of Growth Conditions in Wood for Three White-Rot Fungi and their Cellulaseless Mutants. Biotech. Bioeng., 22, 363-376.

85 Chum, H.L., Douglas, L.J., Feinberg, D.A. et Schroeder, H.A. (1985) Evaluation of Pretreatment of Biomass for Enzymatic Hydrolysis of Cellulose. Rapport technique NREL/TP-231-2183, Golden, CO, National Renewable Energy Laboratory.

86 McDonald, E.C., Howard, J. et Bennet, B. (1983). Chemicals from Forest Products by Supercritical Fluid Extraction. Fluid Phase Equilibria, 10, 337-344.

87 Chou, Y.C.T. (1986) Supercritical Ammonia Pretreatment of Lignocellulosics Materials. Biotech. Bioeng. Symp., 17, 18-32.

88 Pourquié, J. et Glikmans, G. (1986) Steam Explosion and Enzymatic Hydrolysis of Lignocellulosic Material, In $7^{e}$ Symposium international sur les carburants alcoolisés, Paris, 20-23 Octobre 1986. Éditions Technip, Paris, 54-58.

89 Gregg, D. et Saddler, J.N. (1996) A Technico-Economic Assessment of the Pretreatment and Fractionation Steps of a Biomass-to-Ethanol Process. Appl. Biochem. and Biotechnol., 57/58, 711-728.

90 Brownell, H.H. et Saddler, J.N. (1987) Steam Pretreatment of Lignocellulosic Material for Enhanced Enzymatic Hydrolysis. Biotechnol. Bioeng. Symp., 29, 228-235.

91 Rapport final Ascaf/IFP (1992) Valorisation énergétique de la biomasse lignocellulosique. Convention AFME/Ascaf $\mathrm{N}^{\circ} 1.01 .007$.

92 Clark, T.A. et Mackie, K.L. (1987) Steam Explosion Pretreatment of the Softwood Pinus radiata with Sulphur Dioxide Addition. I. Process Optimisation. J. Wood Chem. Techn., 7, 3, 373-403.

93 Mackie, K.L., Brownell, H.H., West, K.L. et Saddler, J.N. (1985) Effect of Sulfur Dioxide and Sulfuric Acid on Steam Explosion of Aspenwood. J. Wood Chem. Techn., 5, 3, 405-425.

94 Fein, J.E., Potts, D., Good, D., Beavan, M., O'Boyle, A., Dahlgen, D., Beck, M.J. et Griffith, R.L. (1991) Development of an Optimal Wood-to-fuel Ethanol Process Utilizing Best Available Technology. In Energy from Biomass and Waste $X V$, Chicago, Institute of Gaz Technology, 745-765.

95 Hohlberg, A.I., Aguilera, J.M., Agosin, E. et San Martin, R. (1989) Catalysed Flash Pretreatment Improve Saccharification of Pine Pinus radiata Sawdust. Biomass 18, 81-93.

96 Wayman, M., Parekh, S., Chornet, E.et Overend, R.P. (1986) $\mathrm{SO}_{2}$ Catalysed Prehydrolysis of Coniferous Wood for Ethanol Production. Biotech. Lett., 8, 10, 749-752.

97 Wayman, M., Seagrave, C. et Parekh, S. (1987) Ethanol Fermentation by Pichia stipitis of Combined Pentose and Hexose Sugars from Lignocellulosics Prehydrolysed by $\mathrm{SO}_{2}$ and Enzymatically Saccharified. Process Biochem., April, 55-59. 
98 Brownell, H.H. (1987) Steam Pretreatment of Wood in Relation to Enzymatic Hydrolysis. Rapport final DSS Contract 05SR, 31926, 4, 5022.

99 N'Diayes, S., Rigal, L., Larocque, P. et Vidal, P.F. (1996). Extraction of Hemicelluloses from Poplar, Populus tremuloides, Using an Extruder-Type Twin-Screw Reactor : a Feasibility Study. Biores. Technol., 57, 61-67.

100 Qiabi, A., Rigal, L. et d Gaset, L. (1994) Comparative Studies of Hemicelluloses Hydrolysis Processes : Application to Various Lignocellulosics Wastes. Industrial Crops and Products , 3, 95-102.

101 Vlasenko, E.Y., Ding, H., Labavitch, J.M. and Shoemaker, S.P. (1996) Enzymatic Hydrolysis of Pretreated Rice Straw, Biores. Technol., 59, 109-119.

102 Hendy, N.A., Wilke, C.R. and Blanch, H.W. (1984) Enhanced Cellulase Production in Fed-Batch Culture of Trichoderma reesei C30. Enz. Microb. Technol., 6, 73-77.

103 Warzywoda, M., Vandecasteele, J.P., and Pourquie, J. (1983) A Comparison of Genetically Improved Strains of the Cellulolytic Fungus Trichoderma reesei. Biotechnology Letters, 5, 243-246.

104 Warzywoda, M., Ferre, V., and Pourquie, J. (1983) Pilot Scale Production of Cellulolytic Enzymes by Trichoderma reesei. Biotechnology and Bioengineering Symposium, 13, 577-580.

105 Warzywoda, M., Larbre, E., et Pourquie, J. (1992) Production and Characterization of Cellulolytic Enzymes from Trichoderma reesei Grown on Various Carbon Sources. Bioresources Technology, 39, 125-130.

106 Marchal, R., Ropars, M., Pourquie, J., Fayolle, F., et Vandecasteele, J.P. (1992) Large Scale Enzymatic Hydrolysis of Agricultural Lignocellulosic Biomass: Conversion into Acetone Butanol. Bioresource Technology, 42, 205-217.

107 Linko, M., Viikari, L. et Suihko (1984) Hydrolysis of Xylan and Fermentation of Xylose to Ethanol. Biot. Adv., 2, 233252.

108 Mandels, M. (1985) Application of Cellulases. In Report, Science and Advanced Technology Laboratory, US Army Natick Research and Developpment Center, Natick, MA, 13, 2, 414-416.

109 Pourquié, J., Warzywoda, M., Chevron, F., Thery, D., Lonchamp, D. et Vandecasteele, J.P. (1988) Biochemistry and Genetics of Cellulose Degradation. FEMS Symposium $\mathrm{n}^{\circ}$ 43, Academic Press, Londres, 2, 71-86.

110 Vallander, L. et Ericksson, K.E. (1985) Enzymatic Saccharification of Pretreated Wheat Straw. Biot. Bioeng., 27, 650-660.

111 Vallander, L. et Ericksson, K.E. (1987) Enzymatic Recirculation in Saccharification of Lignocellulosic Materials. Enz. Microb. Technol., 9, 714-720.

112 Vallander, L. and Eriksson, K.E. (1990), Production of Ethanol from Lignocellulosics Materials : State of the Art. Adv. Bioch. Eng./Biot. 42, 63-95.

113 Castanon, M. et Wilke, C.R. (1980), Adsorption and Recovery of Cellulases during Hydrolysis of Newspaper. Biotechnol. Bioeng., 22, 1037-1053.

114 Reese, E.T. et Mandels, M. (1980, Stability of the Cellulase of Trichoderma reesei under Use Conditions. Biotechnol. Bioeng., 22, 323-335.

115 Mes-Hartree, M., Yu, E.K.C., Reid, I.D. et Saddler, J.N. (1987) Suitability of Aspenwood Biologically Delignified with Pheblia tremelosus for Fermentation to Ethanol or Butanediol. Appl. Microbiol. Biotechnol., 26, 120-125.
116 Clesceri, L.S., Sinitsyn, A.P., Saunders, A.M. et Bungay, H.R. (1985) Recycle of the Cellulase Enzyme Complex After Hydrolysis of Steam Exploded Wood. Appl. Bioch. and Biotechnol., 11, 433-443.

117 Ramos, L.P., Breuil, C. et Saddler, J.N. (1993) The Use of Enzyme Recycling and the Influence of Sugar Accumulation on Cellulose Hydrolysis by Trichoderma Cellulases. Enz. Microb. Technol., 15, 19-25.

118 Sutcliffe, R. et Saddler, J.N. (1986) The Role of Lignin in the Adsorption of Cellulases during Enzymatic Treatment of Lignocellulosic Material. Biot. Bioeng. Symp., 17, 749-762.

119 Chernoglazof, V.M., Ermolova, O.V. and Klyosov, A.A. (1988) Adsorption of High-Purity endo-1,4-B-Glucanases from Trichoderma reesei on Components of Lignocellulosic Materials: Cellulose, Lignin and Xylan. Enz. Microb. Technol., 10, 503-507.

120 Deshpande, M.V. and Eriksson, K.E. (1984), Reutilization of Enzymes for Saccharification of Lignocellulosic Materials. Enz. Microb. Technol., 6, 338-340.

121 Toivola, A., Yarrow, D., van den Bosch, E., van Dijken, J.P., et Scheffers, W.A. (1984) Alcoholic Fermentation of D-Xylose by Yeasts. Appl. Environ. Microbiol., 47, 12211223.

122 du Preez, J.C, et Prior, B.A. (1985) A Quantitative Screening of some Xylose-Fermenting Yeast Isolates, Biotech. Lett., 7, 4, 241-246.

123 du Preez, J.C. (1994), Process Parameters and Environmental Factors affecting D-xylose Fermentation by Yeasts. Enz. Microbiol. Technol., 16, 944-956.

124 Bruinenberg, P.M., van Dijken, J.P. et Scheffers, W.A. (1983) A Theorical Analysis of NADPH Production and Consumption in Yeasts. J. Gen. Microbiol., 129, 953-964.

125 Brown, S.W. and Oliver, S.G. (1982) Isolation of EthanolTolerant Mutants of Yeasts by Continuous Selection. Eur. J. Biotechn., 16, 119-122.

126 Gupthar, A.S. (1992) Segreggation of Altered Parental Properties in Fusions Between Saccharomyces cerevisiae and the D-xylose Fermenting Yeasts Candida shehatae and Pichia stipitis. Can. J. Microbiol., 38, 1233-1237.

127 McMillan, J.D. et Boynton, B.L. (1994) Arabinose Utilization by Xylose-Fermenting Yeasts and Fungi. Appl. Biochem. and Biotechnol., 45/46, 569-584.

128 Wayman, M. et Pareckh, S.R. (1985) Ethanol and Sugar Tolerance of Candida shehatae. Biotech. Lett., 7, 909-912.

129 du Preez, J.C. et van der Walt, J.P. (1983) Fermentation of D-xylose to Ethanol by a Strain of Candida shehatae, Biotech. Lett., 5, 357-362.

130 Jeffries, T. W. (1990) Fermentation of D-xylose and Cellobiose. In Yeast : Biotechnology and Biocatalysis, H. Verachtert et R. De Mot (éds.), Marcel Dekker, NY, 349-394.

131 du Preez, J.C., Bosch, M. et Prior, B.A. (1986) The Fermentation of Hexose and Pentose Sugars by Candida shehatae and Pichia stipitis. Appl. Microbiol. Biotechnol., 23, 228-233.

132 Slininger, S.P., Bothast, R.J., Okos, M.R. et Ladish, M.R. (1985) Comparative Evaluation of Ethanol Production by Xylose-Fermenting Yeasts Presented High Xylose Concentration. Biotech., Lett., 7, 431-436.

133 Tran, A.V. et Chambers, R.P. (1986) Ethanol Fermentation of Red Oak Acid Prehydrolysate by the Yeast Pichia stipitis CBS 5576. Enz. Microbiol. Technol., 8, 439-444.

134 Guebel, D., Cordenons, A., Nudel, C. et Guilietti, A.M (1989) Fermentation of D-xylose to Ethanol by Pichia stipitis 
NRRL Y-7124. Seven Int. Symposium Yeasts, John Wiley \& Sons, S73-S77, New-York.

135 Linko, Y.Y., Kautola, H., Uiotila, S. et Linko, P. (1986) Alcoholic Fermentation of D-xylose by Immobilized Pichia stipitis Yeast. Biotechnol. Lett., 8, 47-52.

136 Schvester, P., Robinson, C.W. et Moo-Young, M. (1983) Xylose Fermentation to Ethanol by Pachysolen tannophilus. Biotech. Bioeng. Symp., 13, 131-152.

137 Delgenes, J.P., Moletta, R. et Navarro, J.M. (1986) The Effet of Aeration on D-xylose Fermentation by Pachysolen tannophilus, Pichia stipitis, Kluyveromyces marxianus and Candida shehatae. Biotech. Lett., 8, 897-900.

138 Woods, M.A. et Millis, N.F. (1985) Effect of Slow Feedings of Xylose on Ethanol Yield by Pachysolen tannophilus. Biotech. Lett., 7, 679.

139 Slininger, S.P., Bothast, R.J., Black, L.T. et McGhee, J.E. (1985), Continuous Conversion of D-xylose to Ethanol by Immobilized Pachysolen tannophilus. Biotech. Bioeng., 24, 2241-2251.

140 Chan, E.C., Ueng, P.P. et Chen L.F. (1986) D-xylose Fermentation to Ethanol by Schizosaccharomyces pombe Cloned with Xylose Isomerase Gene. Biotech. Lett., 4, 231234.

141 Sarthy, A.V., McConaughy, B.L., Lobo, Z., Sundstrom, J.A. Furlong, C.E. et Hall, B.D. (1987) Expression of the E. coli Xylose Isomerase Gene in Saccharomyces cerevisiae. Appl. Environ. Microbiol,. 53, 1996-2000.

142 Amore, R., Wilhelm, M. et Hollenberg, C.P. (1989) The Fermentation of Xylose. An Analysis of the Expression of Bacillus and Actinoplanes Xylose Ismerase Genes in Yeasts. Appl. Microbiol. Biotechnol., 30, 351-357.

143 Chan, E.C., Ueng, P.P., Eder, K.L. et Chen, L.F. (1989) Integration and Expression of the E. coli Xylose Isomerase Gene in Schizosaccharomyces pombe. J. Ind. Microbiol., 3, 723-728.

144 Walfridsson, M., Bao, X., Anderlund, M., Lilius, M. et HahnHägerdal, B. (submitted) Ethanolic Fermentation of Xylose with Saccharomyces cerevisiae Harbouring the Thermophilus xyla Gene Which Expresses an Active Xylose (Glucose) Isomerase.

145 Gong, C.S., Chen, L.-C. et Tsao, G.T. (1981) Production of Ethanol from D-xylose by Using D-xylose Isomerase and Yeasts. Appl. Environ. Microbiol., 41, 430-436.

146 Hahn-Hägerdal, B., Berner, S. et Skoog (1986) Improved Ethanol Production from Xylose with Glucose Isomerase and Saccharomyces cerevisiae Using the Respiratory Inhibitor Azide. Appl. Microbiol. Biotechnol., 24, 287-293.

147 Lastick, S.M., Mohagheghi, A., Tucker, M.P. et Grohmann, K. (1990) Simultaneous Saccharification and Isomerization of Xylose to Ethanol at High Xylose Concentration. Applied Biochemistry and Biotech., 24/25, 431-439.

148 Kötter, P. et Ciriacy, M. (1993) Xylose Fermentation by Saccharomyces cerevisiae. Appl. Microbiol. Biotechnol., 38, 776-783.

149 Tantirungkij, M., Izuishi, T., Seki, T. et Yoshida, T. (1994) Fed-Batch Fermentation by a Fast Growing Mutant of Xylose-assimilating Recombinant Saccharomyces cerevisiae. Appl. Microbiol. Biotechnol., 41, 8-12.

150 Ho, N.W.Y. et Tsao, G.T. (1995) Recombinant Yeasts for Effective Fermentation of Glucose and Xylose. Brevet PCT WO95/11362.

151 Hallborn, J., Walfridsson, M., Airaksinen, U., Ojamo, H., Hahn Hägerdal, B., Penttilä, M. et Keränen (1991) Xylitol Production by Recombinant Saccharomyces cerevisiae. Bio/Technology., 9, 1090-1095.
152 Kötter, P., Amore, R., Hollenberg, C.P. et Ciriacy, M. (1990) Isolation and Characterization of the Pichia stipitis Xylitol Dehydrogenase Gene, XYL2, and Construction of a Xyloseutilizing Saccharomyces cerevisiae Transformant. Curr. Gen., 18, 413-500.

153 Carreira, L.H., Wiegel J. et Ljungdahl (1983) Production of Ethanol from Biopolymers by Anaerobic, Thermophilic, and Extreme Thermophilic Bacteria: I. Regulation of Carbohydrate Utilization in Mutants of Thermoanaerobacter ethanolicus. Biotech. and Bioeng. Symp., 13, 183-191.

154 Lacis, L.S. et Lawford, H.G. (1988) Ethanol Production from Xylose by Thermoanaerobacter ethanolicus in Batch and Continuous Culture. Arch. Microbiol., 150, 48-55.

155 Lacis, L.S. et Lawford, H.G. (1989) Analysis of the Variation of Ethanol Yield from Glucose or Xylose with Continuously Grown Thermoanaerobacter ethanolicus. Appl. Biochem. and Biotechnol., 20/21, 479-490.

156 Schell, D.J., McMillan, J.D., Philippidis, G.P., Hinman, N.D. et Riley, C. (1992) Ethanol from Lignocellulosic Biomass. In Adavances in Solar Energy, K.W. Boer (éd.), American Energy Society, Boulder, CO, 373-448.

157 Ben-Bassat, T.K. et Zeikus, J.G. (1981) Ethanol Production by Thermophilic Bacteria: Fermentation of Cellulosic Substrates by Cocultures of Clostridium thermocellum and Clostridium thermohydrosulfuricum. Appl. Environ. Microbiol., 41, 1337-1343.

158 Weigel, J., Carriera, L.H., Mothershed, C.P. et Puls, J. (1983) Production of Ethanol from Biopolymers by Anaerobic, Thermophilic and Extreme Thermophilic Bacteria. II. Thermoanaerobacter ethanolicus JW200 and its Mutants in Batch Cultures and Resting Cell Experiments. Biotechn. and Bioeng. Symp., 13, 193-205.

159 Hartley, B.S., Baghaei-Yazdi, N., Javed M., San Martin, R. et Leak, D.J. (1993) Liquid Fuels plus Cellulose Fibres from Agricultural Wastes. In Straw. A Valuable Raw Material, PIRA Intn'l, Leatherhead, Royaume-Uni., 2a, 37.

160 Lacis, L.S. et Lawford, H.G. (1991) Thermoanaerobacter ethanolicus Growth and Product Yield from Elevated Levels of Xylose or Glucose in Continuous Cultures. Appl. Environ. Microbiol., 57, 579-585.

161 Liu, H.S., Hsu, H.W. et Sayler, G.S. (1988) Bioconversion of D-xylose and Pretreated Oak Sawdust to Ethanol Using Clostridium thermosaccharolyticum by Batch and Continuous Up-Flow Reactors. Biotechnol. Prog., 4, 40-46.

162 Lynd, L.R., Cushman, J.H., Nichols, R.J. et Wyman, C.E. (1991) Fuel Ethanol from Cellulosic Biomass. Science, 251, 1318-1323.

163 Zhang, M., Eddy, C., Deanda, K., Finkelstein, M. et Picataggio, S. (1995) Metabolism Engineering of a Pentose Metabolism Pathway in Ethanologenic Zymomonas mobilis. Science, 267, 240-243.

164 Deanda, K., Zhang, M., Eddy, C. et Picatagio, K.S. (1996) Development of an Arabinose-Fermenting Zymomonas mobilis Strain by Metabolic Pathway Engineering. Appl. Environ. Microbiol., 62, 44-65.

165 Ingram, L.O. et Conway, T. (1988) Expression of Different Levels of Ethanologic Enzymes from Zymomonas mobilis in Recombinant Strains of E. coli. Appl. Environ. Microbiol., $\mathbf{5 4}, 397-404$.

166 Altherthum, F. et Ingram, L.O. (1989) Efficient Ethanol Production from Glucose, Lactose, and Xylose by Recombinant E. coli. Appl. Environ. Microbiol., 55, 8, 19431948.

167 Ohta, K., Altherthum, F. et Ingram, L.O. (1990) Effects of Environnmental Conditions on Xylose Fermentation by Recombinant E. coli. Appl. Environ. Microbiol., 56, 463-465. 
168 Lawford, H.G. et Rousseau, J.D. (1991a) Ethanol Production by Recombinant $E$. coli Carrying Genes from Zymomonas mobilis. Appl. Biochem. and Biotechnol., 28/29, 221-236.

169 Lawford, H.G. et Rousseau, J.D. (1992) Fuel Ethanol from Corn Residue Prehydrolysate by a Patented Ethanologenic $E$. coli B. Biotech. Lett., 14, 421-426.

170 Hahn-Hägerdal, B., Hallborn, J., Jeppson, H., Olsson, L., Skoog, K. et Walfridsson, M. (1993) Pentose Fermentation to Alcohol. Saddler, J.N., éd., Wallingford, Royaume-Uni, CAB International, 231-290.

171 Ohta, K., Beall, D.S., Meija, J.P., Shanmugam, K.T. et Ingram, L.O (1991) Genetic Improvement of E. coli for Ethanol Production: Chromosal Integration of Zymomonas mobilis Genes Encoding Pyruvate Decarboxylase and Alcohol Dehydrogenase II. Appl. Environ. Microbiol., 57, 893-900.

172 Hespell, R.B., Wyckoff, H., Dien, B.S. et Bothast, R.J. (1996) Stabilization of Pet Operon Plasmids and Ethanol Production in E. coli Strains Lacking Lactate Dehydrogenase and Puruvate Formate-Lyase Activities. Appl. Environ. Microbiol., 62, 12, 4594-4597.

173 Lawford, H.G. et Rousseau, J.D. (1991b) Fuel Ethanol from Hardwood Hemicellulose Hydrolysate by Genetically Engineered E. coli B Carrying Genes from Zymomonas mobilis. Biotech. Lett., 13, 191-196.

174 Beall, D.S., Ohta, K. et Ingram, L.O. (1991) Parametric Studies of Ethanol Production from Xylose and Other Sugars by Recombinant E. coli. Biotechnol. Bioeng., 38, 296-303.

175 Ohta, K., Beall, D.S., Meija, J.P., Shanmugam, K.T. et Ingram, L.O (1991b) Metabolic Engineering of Klebsiella oxytoca M5A1 for Ethanol Production from Xylose and Glucose. Appl. Environ. Microbiol., 57, 2810-2815.

176 Tolan, J.S. et Finn, R.K. (1987b) Fermentation of D-xylose to Ethanol by Genetically Modified Klebsiella planticola. Appl. Environ. Microbiol., 53, 2039-2044.

177 Feldmann, S., Sprenger, G.A. et Sahm, H. (1989) Ethanol Production from Xylose with a Pyruvate-Formate-Lyase Mutant of Klebsiella planticola Carrying a Pyruvate Decarboxylase Gene from Zymomonas mobilis. Appl. Microbiol. Biotechnol., 31, 152-157.

178 Clark, T.A. et Mackie, K.L. (1984) Fermentation Inhibitors in Wood Hydrolysates Derived from Softwood Pinus radiata. J. Chem. Techn. Biotechnol., 34B, 101-110.

179 Yu, S., Wayman, M. et Parekh, S.K. (1987) Fermentation to Ethanol of Pentose-containing Spent Sulfite Liquor. Biotechn. Bioeng., 29, 1144-1150.

180 Pareckh, S.R., Pareckh, R.S. et Wayman, M. (1987) Fermentation of Wood-Derived Acid Hydrolysates in a Batch Bioreactor and in a Continuous Dynamic Immobilized Cell Bioreactor by Pichia stipitis. Proc. Biochem., juin, 85-91.

181 Jeffries, T.W. et Sreenath, H.K (1988) Fermentation of Hemicellulosic Sugars and Sugar Mixtures by Candida shehatae. Biotechnol. Bioeng., 31, 502-506.

182 Parekh, S.R., Yu, S. et Wayman, M. (1986) Adaptation of Candida shehatae and Pichia stipitis to Wood Hydrolysates for Increased Ethanol Production. Appl. Microbiol. Biotechnol., 25, 300-304.

183 Barbosa, M.F.S., Beck, M.J., Fein, J.E., Potts, D. et Ingram, L.O. (1992) Efficient Fermentation of Pinus sp. Acid Hydrolysates by an Ethanologenic Strain of E. coli. Appl. Environ. Microbiol., 58, 1382-1384.

184 Olson, L. et Hahn-Hägerdal, B. (1996) Fermentation of Lignocellulosic Hydrolysates for Ethanol Production. Enzyme Microbiol. Technol., 18, 312-331.
185 Delgenes, J.P., Moletta, R. et Navarro, J.M. (1990) Acid Hydrolysis of Wheat Straw and Process Considerations for Ethanol Fermentation by Pichia stipitis Y7124. Proc. Biochem., 25, 132-135.

186 Jeffries, T.W. (1984a) Mutants of Pachysolen tannophilus Showing Enhanced Rates of Growth and Ethanol Formation from D-Xylose. Enz. and Microb. Technol., 6, 254-258.

187 Wilson, J.J., Deschatelets, L. et Nishikawa, N.K. (1989) Comparative Fermentability of Enzymatic and Acid Hydrolysates of Steam-Pretreated Aspenwood Hemicellulose by Pichi stipitis CBS 5776. Appl. Microbiol. Biotechnol., 31, 592-596.

188 Ferrari, M.D., Neirotti, E., Albornoz, C. et Saucedo, E. (1992) Ethanol Production from Eucalyptus Wood Hemicellulose Hydrolysate by Pichia stipitis. Biotechnol. Bioeng., 40, 753-759.

189 Van Zyl, C., Prior, B.A. et du Preez, J.C. (1991) Acetic Acid Inhibition of D-Xylose Fermentation by Pichia stipitis. Enz. Microbiol. Technol., 13, 82-86.

190 Roberto, J.C., Lacis, L.S., Barbosa, M.F.S. et de Mancilha, I.M. (1991) Utilization of Sugar Cane Bagasse Hemicellulosic Hydrolysate by Pichia stipitis for the Production of Ethanol. Proc. Biochem., 26, 15-21.

191 Grohmann, K. (1993) Simultaneous Saccharification and Fermentation of Cellulose Substrates to Ethanol. In Bioconversion of Forest and and Agricultural Plant Residues, Saddler, J.N., éd., Wallingford, Royaume-Uni, CAB International, 183-209.

192 Gonde, P., Blondin, B., Leclerc, M., Ratomahenina, R., Arnaud, A. et Galzy, P. (1984a) Fermentation of Cellodextrins by Different Yeast Strains. Appl. Environ. Microb., 48, 265-269.

193 Lastick, S.M., Spindler, D.D., Terrel, S. et Grohmann, K. (1984) The Simultaneous Saccharification and Fermentation of Cellulose. Biotech., 84, 277-289.

194 Cavazzoni, A. et Adami, A. (1987a) Cellobiose Fermentation by Some Strains of Hansenula Yeasts. Annals of Microbiology, 37, 1-5.

194b Cavazzoni, A. et Adami, A. (1987b) Cellobiose Fermentation by Immobilized Cells of Some Yeasts. Annals of Microbiology, 37, 127-133.

195 Spindler, D.D., Wyman, C.E., Grohmann, K. et Philippidis, G.P. (1992) Evaluation of the Cellobiose-Fermenting Yeast Brettanomyces custersii in the Simultaneous Saccharification and Fermentation of Cellulose. Biotech. Lett., 14, 403-407.

196 Doran, J.D. et Ingram, L.O. (1993) Fermentation of Crystalline Cellulose to Ethanol by Klebsiella oxytoca Containing Chromosomally Integrated Zymomonas Genes. Biotechnol. Prog., 9, 533-538.

197 Laplace, J.M., Delgenes, J.P., Moletta, R. et Navarro, J.M. (1992) Alcoholic Glucose and Xylose Fermentations by the Coculture Process. Compatibility and Typing of Associated Strains. Can. J. Microbiol., 25, 132-135.

198 Ballesteros, I., Ballesteros, M., Cabanas, A., Carrasco, J., Martin, C., Negro, M.J., Saez, F. et Saez, R. (1991) Selection of Thermotolerant Yeast for Simultaneous Saccharification and Fermentation (SSF) of Cellulose. Appl. Biochem. and Biotechnol., 28/29, 307-315.

199 Grootjen, D.R.J., Meijlink, L.H.H.M., van der Lans, R.G.J.M. et Luyben, K.Ch.A.M. (1990) Cofermentation of Glucose and Xylose with Immobilized Pichia stipitis and Saccharomyces cerevisiae. Enzyme Microbiol. Technol., 12, 860-864.

200 Grootjen, D.R.J., Lansen, M.L., van der Lans, R.G.J.M. et Luyben, K.Ch.A.M. (1991) Reactors in Series for the 
Complete Conversion of Glucose and Xylose Mixtures by P. stipitis and S. cerevisiae. Enzyme Microbiol. Technol., 13, 828-833.

201 Beck, M.J., Johnson, R.D. et Becker, J.C. (1990) Ethanol Production from Glucose/Xylose Mixes by Incorporating Microbes in Selected Fermentation Schemes. Appl. Biochem. and Biotechnol., 24/25, 415-424.

202 Laplace, J.M., Delgenes, J.P., Moletta, R. et Navarro, J.M. (1993) Ethanol Production from Glucose and Xylose by Separated and Coculture Processes Using High Cell Density System. Biotech. Proc. Biochem., 28, 519-525.

203 Deverell, K.F. (1983) Ethanol Production from Wood Hydrolysates Using Pachysolen tannophilus. Biotech. Lett., 5, 475-480.

204 Lindsay, S.E., Bothast, R.J. et Ingram, L.O. (1995) Improved Strains of Recombinant E. coli for Ethanol Production from Sugar Mixtures. Appl. Microbiol. Biotechnol., 43, 70-75.

205 Spindler, D.D., Wyman, C.E., Mohagheghi, A. et Grohmann, K. (1988) Thermotolerant Yeast for Simultaneous Saccharification and Fermentation (SSF) of Cellulose to Ethanol. Appl. Biochem. and Biotechnol., 17, 279-293.

206 Spindler, D.D., Wyman, C.E., Grohmann, K. et Mohagheghi, A. (1989a) Simultaneous Saccharification and Fermentation of Preatreated Wheat Straw to Ethanol with Selected Yeast Strains and b-Glucosidase Supplementation. Appl. Biochem. and Biotechnol., 20-21, 529-540.

207 Spindler, D.D., Wyman, C.E., Grohmann, K. et Torget, R.W. (1990) Evaluation of Pretreated Woody Crops for the Simultaneous Saccharification and Fermentation Process. Appl. Biochem. and Biotechnol., 24-25, 275-286.

208 Szczodrak, J. et Targonski, Z. (1988) Selection of Thermotolerant Yeast Strains for Simultaneous Saccharification and Fermentation of Cellulose. Biot. Bioeng., 31, 301-303.

209 Tagaki, M., Abe, S., Suzuki, S., Evert, G.H. et Yata, N. (1977) A Method of Production of Alcohol Directly from Yeast. Proc. Bioconv. Symp., IIT 551-571.

210 McCracken, L.D. et Gong, C.S. (1982) Fermentation of Cellulose and Hemicellulose Carbohydrates by Thermotolerant Yeasts. Biot. Bioeng. Symp., 12, 91-102.

211 Spangler, D.J. et Emert, G.H. (1986) Simultaneous Saccharification/Fermentation with Zymomonas mobilis. Biot. Bioeng., 28, 115-118.

212 Barnett, J.A., Payne, R.W. et Yarrow, D. (1985) Yeasts Characteristics and Identification, Cambridge University Press, Cambridge, Royaume-Uni.

213 Beall, D.S., Ingram, L.O., Ben-Bassat, A., Doran, J.B. Fowler, D.E., Hall, R.G. et Wood, B.E. (1992) Conversion of
Hydrolysate of Corn Cobs and Hulls into Ethanol by Recombinant E. coli B Containing Integrated Genes for Ethanol Production. Biotech. Lett., 14, 857-862.

214 Ghose, T.K., Roychoudhury, P.K. et Ghosh, P. (1984) Simultaneous Saccharification and Fermentation (SSF) of Lignocellulosics to Ethanol Under Vacuum Cycling and Step Feeding. Biotechn. Bioeng., 26, 377-381.

215 Schell, D.J., Grohmann, K., Wyman, C.E. et Himmel, M.E. (1992) Potentials for Fuels from Biomass and Wastes. Rowell, R.M., Schultz, T.P. et Narayan, R. (éds), Emerging Technologies for Materials and Chemicals from Biomass, ACS Symposium Series $\mathrm{n}^{\circ}$ 476, American Chemical Society, Washington, DC, États-Unis, 354-392.

216 Philippidis, G.P. (1994) Cellulase Production Technology. In Enzymatic Conversion of Biomass for Fuels Production, M.E. Himmel, J.O. Baker et R.P. Overand, éds., American Chemical Society, Waschington, DC 188-217.

217 Dale, M. et Lee, S. (1995) A Laboratory and Pilot Plant Scaled Continuous Stirred Reactor Separator for the Production of Ethanol from Sugars Corn Grits, Starch or Biomass Streams. 2nd Biomass Conference of the Americas, 996.

218 Philippidis, G.P. et Smith, T.K. (1995) Limiting Factors in the Simultaneous Saccharification and Fermentation Process for Conversion of Cellulosic Biomass to Fuel Ethanol. Appl. Biochem. and Biotechnol., 51/52, 117-124.

219 Spindler, D.D., Wyman, C.E., Mohagheghi, K. et Grohmann, K. (1991) The Simultaneous Saccharification and Fermentation of Pretreated Woody Crops to Ethanol. Appl. Biochem. and Biotechnol., 28/29, 773-785.

220 Halliwell, G. et Phillips, T. (1987) Synthetis and Activity of Cellulase Produced by Strains of the Thermophilic, Anaerobic, Cellulolytic Bacterium Clostridium thermocellum. Biomass for Energy and Industry. Proceedings of the 4th ECC Conference Orleans. Grassy, G. et al. (éds), Elsevier, Londres, 709.

221 Ahn, H.J. et Lynd, L.R. (1996) Cellulose Degradation and Ethanol Production by Thermophilic Bacteria Using Mineral Growth Medium. Appl.Bioch. and Biotechn., 57/58, 599-605.

222 Klapatch, T.R., Hogsett, D.A.L., Baskaran, S., Pal, S. et Lynd, L.R. (1994) Organism Development and Characterization for Ethanol Production Using Thermophilic Bacteria. Appl. Bioch. Biotech., 45/46, 209-223.

223 McMillan, J.D. (1996) Hemicellulose Conversion to Ethanol. In Handbook on Bioethanol: Production and Utilization, édité par Wyman, chap. 13, 287-313.

Manuscrit final reçu en juin 1998 